Narrative Review

\title{
e Nerve Entrapment Headaches at the Temple: Zygomaticotemporal and/or Auriculotemporal Nerve?
}

Helen W. Karl, MD'1, and Andrea M. Trescot, MD²

\footnotetext{
From: 'Seattle Children's Hospital| University of Washington, Seattle, WA; ${ }^{2}$ Pain and Headache Center, Eagle River, AK

Address Correspondence: Andrea Trescot, MD Pain and Headache Center 12836 Old Glenn Hwy Suite 2 Eagle River, AK 99577 E-mail:

DrTrescot@gmail.com

Disclaimer: There was no external funding in the preparation of this manuscript. Conflict of interest: Each author certifies that he or she, or a member of his or her immediate

family, has no commercial association (i.e., consultancies, stock ownership, equity interest, patent/licensing arrangements, etc.) that might pose a conflict of interest in connection with the submitted manuscript.

Manuscript received: 01-07-2018 Revised manuscript received: 04-16-2018 Accepted for publication: 08-17-2018

Free full manuscript: www.painphysicianjournal.com
}

Background: Temple headaches are common, yet the anatomic etiology of headaches in this region is often confusing. One possible cause of temple headaches is dysfunction of the auriculotemporal nerve (ATN), a branch of the third division of the trigeminal nerve. However, the site of pain is often anterior to the described path of the ATN, and corresponds more closely to a portion of the path of a small branch of the second division of the trigeminal nerve called the zygomaticotemporal nerve (ZTN)

Objectives: We present the anatomic and clinical differences between these 2 nerves and describe treatment approaches. Diagnosis is made by physical examination of the temporal fossa and the temporomandibular joint, and injection of local anesthetic over the tenderest nerve.

Results: In general, treatments of headaches that generated from the peripheral nerve attempt to neutralize the pain origin using surgical or interventional pain techniques to reduce nerve irritation and subsequently deactivate stimulated migraine centers.

Conclusions: Treatment of temporal nerve entrapment includes medications, nerve injections, dental appliances, cryoneuroablation, chemical neurolysis, neuromodulation, and surgical decompression.

Key Words: Headache, migraine, trigeminal nerve, Frey's syndrome, zygomaticotemporal nerve, auriculotemporal nerve, temple pain, jaw pain, ear pain, tooth pain

Pain Physician 2019: 22:E15-E36

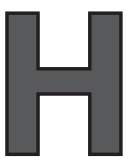

eadaches are one of the most prevalent neurologic disorders. They affect about half of all adults worldwide at least once a year, occur more than 2 weeks per month in $1.7-4 \%$, and are the third leading cause of years lost to disability (1). Headache patterns have provided practitioners and researchers with basic guidelines to understand and treat these debilitating conditions (2).
Many now propose that headaches, including some migraines, are not always isolated intracranial phenomena, but rather the result of interactions between the intracranial components of the brain and the extracranial nerves. At the beginning of this century, plastic surgeons noted relief of migraines with corrugator muscle resection (3) or injection of botulinum toxin, suggesting a peripheral headache trigger. Headache specialists see 
patients who have had head or neck injuries followed by disabling migrainous headaches, which respond only modestly to migraine-specific pain medications (4). These headaches are thought to have an extracranial origin, the result of peripheral nerve damage in the head or neck sustained during the injury $(5,6)$. This peripheral nerve irritation may secondarily activate migraine centers in the brain and generate the associated migrainous symptoms. Increasing basic research into the trigeminovascular system (the relationship between the meninges, trigeminal afferent nerves and their connections in the brainstem) and the trigeminocervical complex (the relationship between the trigeminal nerve and the upper cervical nerves) provides cumulative mechanistic evidence for these observations (7-10).

The temple is a common headache site (visualize the many headache patients rubbing or pressing their temples for relief). Calandre et al (11) investigated the presence of head and neck trigger points that elicited referred pain in 94 migraine patients and 32 healthy controls. They found that $94 \%$ of the migraine patients had at least one trigger point, with $43 \%$ of these points in temporal areas. Dysfunction of both the zygomaticotemporal nerve (ZTN) (12-14) and the auriculotemporal nerve (ATN) (15-18) has been associated with "migraine headaches" centered on the temple, but there is often confusion between them.
Surgical approaches to treatment of headaches in the temple region not manageable with non-operative approaches have been described $(14,19,20)$ and are increasingly accepted $(19,21)$. Of these, most reports focus on ZTN entrapment; indeed, this nerve has been classified as one of several major migraine trigger sites (Fig. 1 site II) (21). Although the ATN had been considered a relatively minor migraine trigger site (Fig. 1 site V) (21), extensive anatomic review of its peripheral course has increased the understanding of its potential contributions to migraine pain in this area (16), including documented persistent ATN pathology after treatment of ZTN entrapment (22). Other authors have commented on the interdependence between the 2 nerves (23).

Distinguishing between dysfunction of the ZTN or the ATN as the source of any particular problem can be difficult because of the complex and variable anatomy of the area between where the nerves emerge from the skull, including confusion regarding the anatomic layers of the temporoparietal region (Fig.2), and their termination in the skin of the temple (24). The purpose of this paper is to provide a direct comparison of what is known of the anatomy of each nerve (including their common anatomical variations), and review some methods to diagnose and treat painful conditions that result when irritation of one or both nerves contributes to headaches in this area.

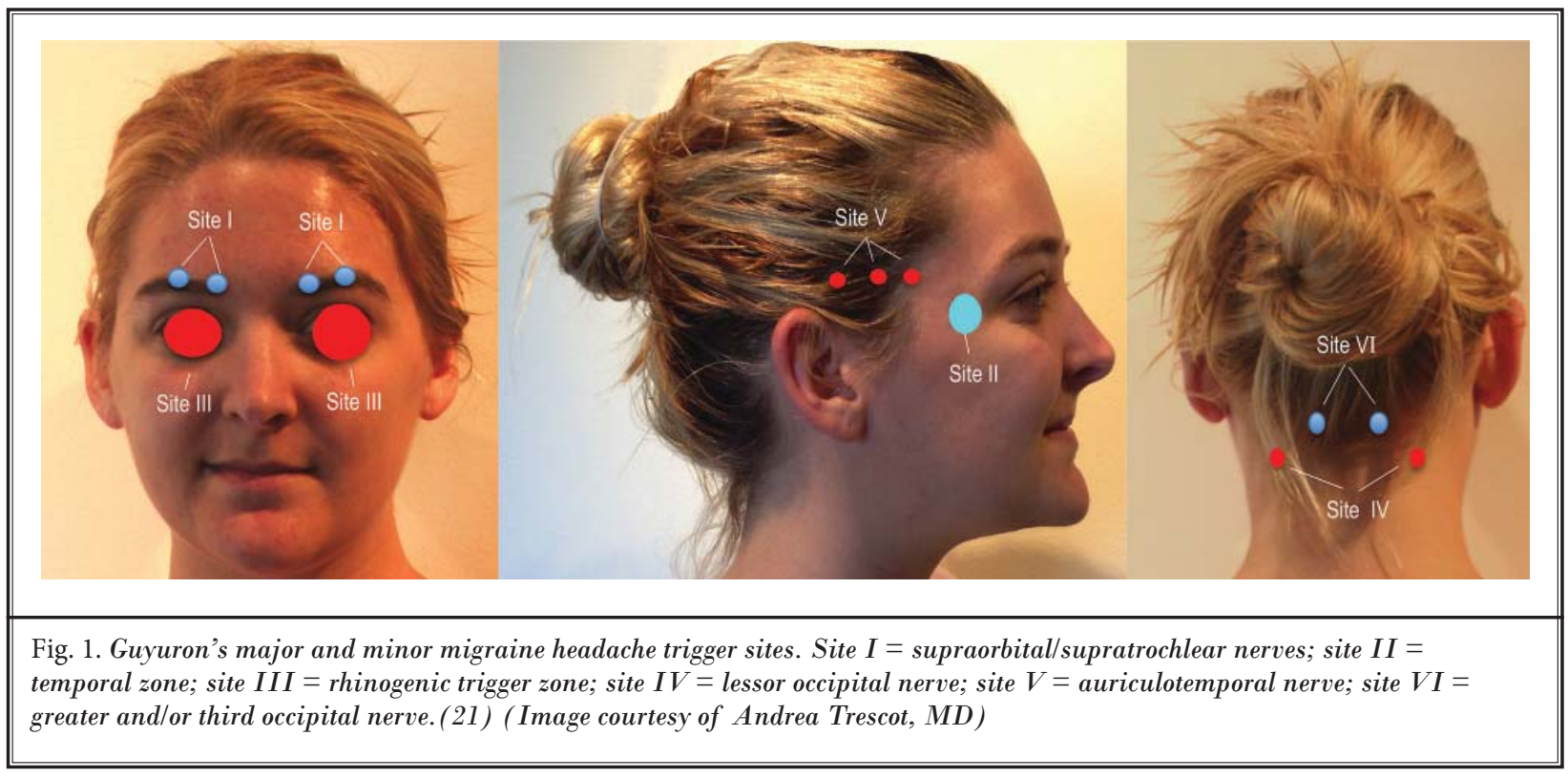




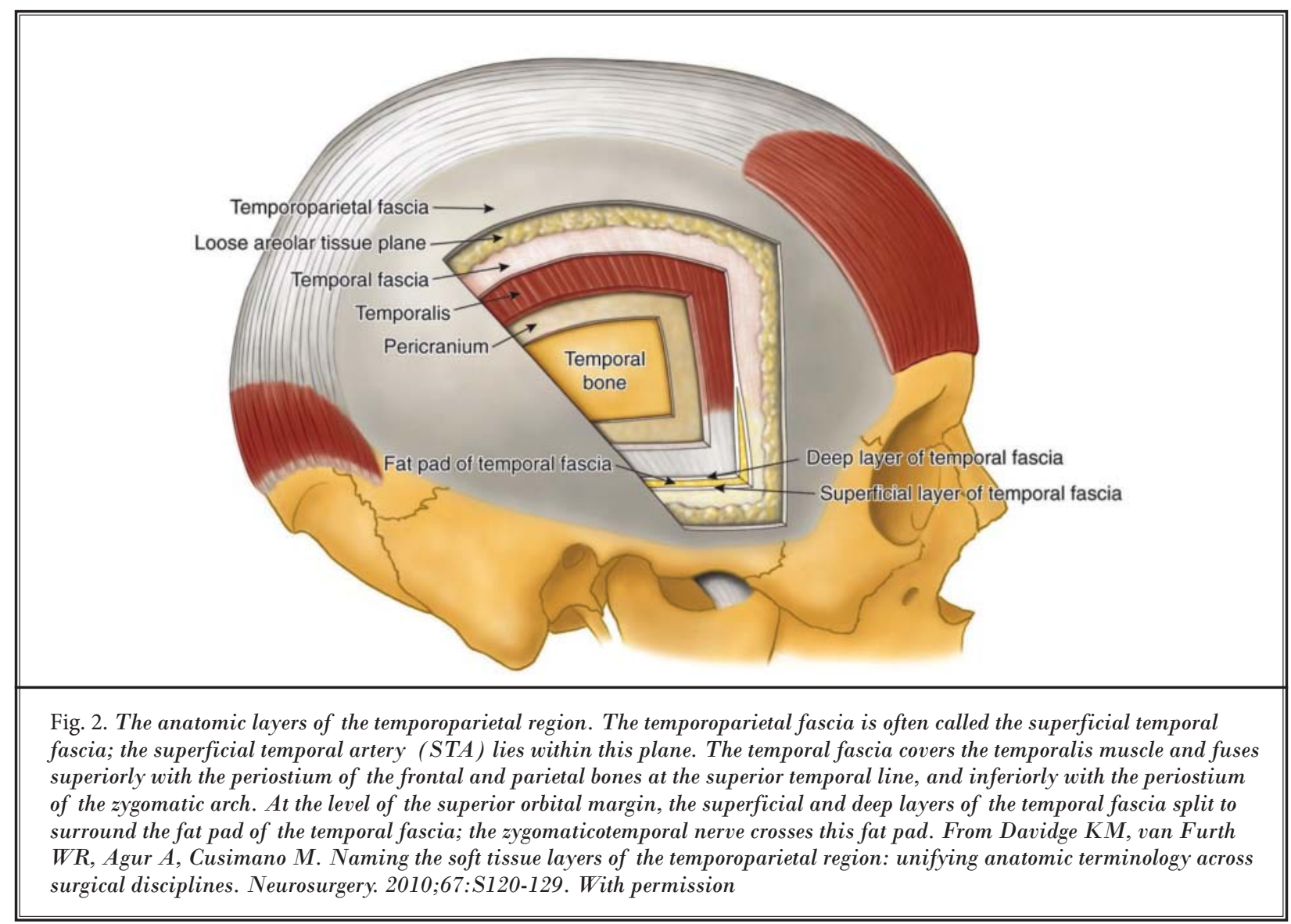

\section{Anatomy}

The temporal fossa is a shallow depression on the outside of the skull between the superior temporal line and the zygomatic arch. Its medial wall is formed by 4 bones: the frontal and parietal bones superiorly and the greater wing of the sphenoid and the squamous portion of the temporal inferiorly (Fig. 3). The H-shaped site where the sutures between these bones meet is called the pterion. The infratemporal fossa is the region medial and inferior to the zygoma. It is almost entirely filled with at least parts of the 4 muscles of mastication (the lateral pterygoid, medial pterygoid, masseter and temporalis muscles). The pterygopalatine fossa is medial to and continuous with the infratemporal fossa.

The trigeminal nerve (the 5th cranial nerve, often designated by its Roman numeral, V) is the sensory nerve of the head (25). As part of the trigeminovascular system, it is increasingly implicated in the genesis of migraine headaches (7-10). The trigeminal nerve consists mostly of somatic afferent (sensory) fibers with some special visceral efferent (motor) fibers in its mandibular (V3) division. Its spinal nucleus (the trigeminal ganglion) is the source of pain, temperature, and touch in all 3 divisions. The trigeminal nerve emerges from the pons at the level of the 4th ventricle and soon splits into its 3 somatic divisions, each of which leaves the middle cranial fossa via a different passage. The ophthalmic division (V1) enters the orbit through the superior orbital fissure, the maxillary division (V2) enters the pterygopalatine fossa via the foramen rotundum, and the mandibular division (V3) goes into the infratemporal fossa (lateral to and continuous with the pterygopalatine fossa) by way of the foramen ovale. Two peripheral branches of the trigeminal nerve, one from each of its lower 2 divisions (the ZTN from V2 and the ATN from V3), terminate in the soft tissues over the temporoparietal region and are responsible for similar headache symptoms. The anatomy of the soft tissue layers in this region is complex, and historically 


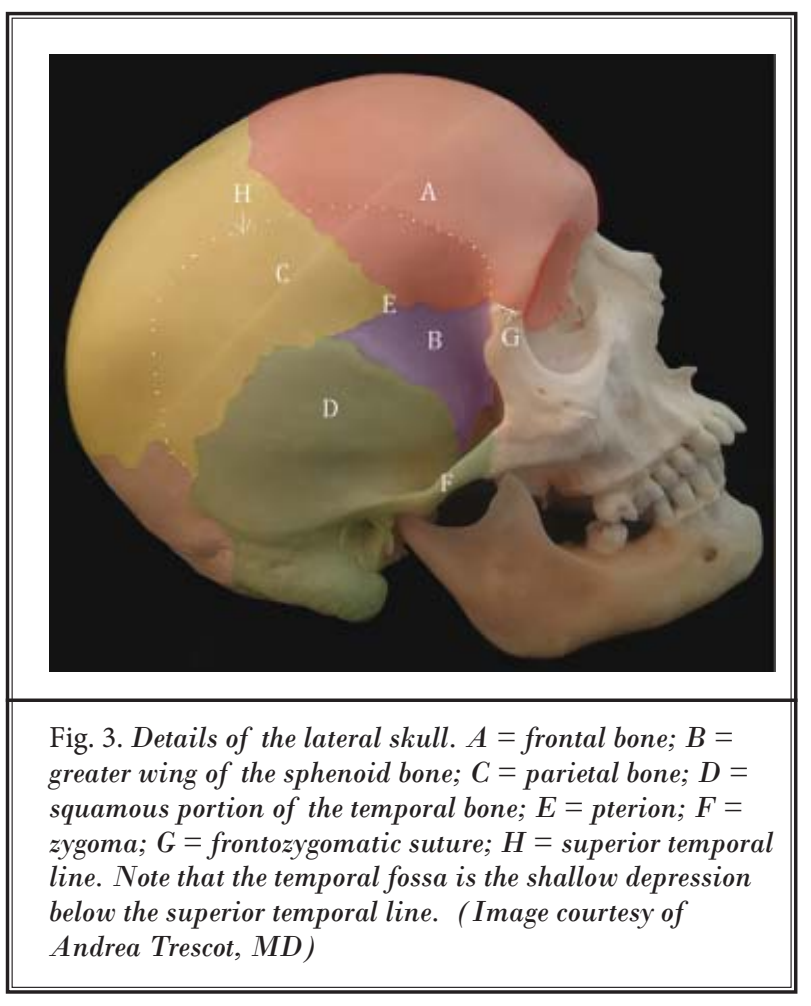

inconsistent nomenclature has been used to identify them. Where possible, the naming system proposed by Davidge et al (24) will be used in this report (Fig. 2).

\section{Anatomy of the Zygomaticotemporal Nerve}

The ZTN is a major terminal branch of the maxillary (second, V2) division of the trigeminal nerve; it crosses the orbit, a canal in the zygomatic bone and the temporalis muscle to end in the skin of the anterior temple near the lateral eyebrow (Table 1).

The zygomatic nerve (ZN) separates from the maxillary nerve in the pterygopalatine fossa, enters the floor of the lateral orbit through the infraorbital fissure, and divides into the ZTN and zygomaticofacial (ZFN) nerves (Fig. 4). The ZTN is joined by a communicating branch from the lacrimal nerve; it then may cross a small opening in the frontal process of the zygomatic bone called the zygomaticotemporal foramen (ZTF) or pass directly behind the lateral rim of the orbit. The ZTN enters the temporal fossa approximately $1 \mathrm{~cm}$ below the frontozygomatic suture (FZ suture) (26). Unlike the ZFN and many other nerves, the ZTN is not associated with a satellite artery (27). Hwang and colleagues (26)

Table 1. Anatomy and entrapment.

\begin{tabular}{|c|c|c|}
\hline Anatomy & ZTN & ATN \\
\hline Origin & $\begin{array}{l}\text { Maxillary division of the trigeminal nerve (V2) exits the } \\
\text { middle cranial fossa via the foramen rotundum. }\end{array}$ & Mandibular division of the trigeminal nerve (V3) (51) \\
\hline General route & $\begin{array}{l}\text { The zygomatic nerve (ZN) separates from the maxillary } \\
\text { nerve in the pterygopalatine fossa (continuous laterally } \\
\text { with the infratemporal fossa), enters the lateral orbit } \\
\text { (floor) through the infraorbital fissure where it divides } \\
\text { into the zygomaticofacial (ZFN) and zygomaticotemporal } \\
\text { (ZTN) nerves. The ZTN enters the temporal fossa } \\
\text { as a single trunk via a canal in the frontal process of } \\
\text { the zygomatic bone, and runs between the bone and } \\
\text { the temporalis muscle. Approximately } 2 \mathrm{~cm} \text { above the } \\
\text { zygomatic arch, the ZTN pierces the temporal fascia to } \\
\text { end in the skin over the anterior temple. } \\
\text { Branches may communicate with the lacrimal nerve, the } \\
\text { auriculotemporal nerve (ATN) and/or the facial nerve. }\end{array}$ & $\begin{array}{l}\text { In the infratemporal fossa (continuous medially with the } \\
\text { pterygopalatine fossa), the ATN surrounds the middle meningeal } \\
\text { artery. Its } 6 \text { named branches separate within the parotid gland } \\
\text { at the posterior border of the mandible just below the external } \\
\text { auditory meatus. The main branch (also called the superficial } \\
\text { temporal ramus) runs very close to the medial capsule of the } \\
\text { temporomandibular joint (TMJ) (46) then loops below the } \\
\text { posterior part of the zygomatic arch and becomes progressively } \\
\text { superficial. It travels within the temporoparietal fascia near } \\
\text { (and directly related to in } 34 \% \text { of } 50 \text { cadaver hemiheads) } \\
\text { the superficial temporal artery (STA) to terminate in the } \\
\text { subcutaneous tissue of the posterior temple. (16) Smaller } \\
\text { branches communicate with the facial nerve, and innervate the } \\
\text { external auditory meatus and anterior auricle (51). }\end{array}$ \\
\hline $\begin{array}{l}\text { Sensory } \\
\text { distribution }\end{array}$ & Skin over the anterior temple & $\begin{array}{l}\text { TMJ (also supplied by the deep temporal nerve and the } \\
\text { masseteric nerve), parotid gland, external auditory canal, } \\
\text { tympanic membrane, superior auricle and the skin over the } \\
\text { temple posterior to that of the ZTN }\end{array}$ \\
\hline $\begin{array}{l}\text { Motor } \\
\text { innervation }\end{array}$ & None & None \\
\hline $\begin{array}{l}\text { Autonomic } \\
\text { innervation }\end{array}$ & $\begin{array}{l}\text { Post-ganglionic parasympathetic fibers: from the } \\
\text { superior salivatory nucleus, leave the facial nerve } \\
\text { as part of the greater petrosal nerve, synapse in the } \\
\text { pterygopalatine ganglion, travel as part of the zygomatic } \\
\text { nerve and terminate in the lacrimal gland to increase tear } \\
\text { production }(12,27) \text {. }\end{array}$ & $\begin{array}{l}\text { Post-ganglionic parasympathetic fibers: from the inferior } \\
\text { salivatory nucleus, leave the glossopharyngeal nerve as part of } \\
\text { the tympanic nerve, synapse in the otic ganglion, travel as part of } \\
\text { the auriculotemporal nerve and terminate in the parotid gland to } \\
\text { increase saliva production (16). } \\
\text { Sympathetic innervation of the scalp and face }\end{array}$ \\
\hline
\end{tabular}


Nerve Entrapment Headaches at the Temple

Table 1 (cont.). Anatomy and entrapment.

\begin{tabular}{|l|l|l||}
\hline Anatomy & ZTN & ATN \\
\hline Entrapment & $\begin{array}{l}\text { In the orbit }(29,33) . \\
\text { Theoretically, at or near the bony canal in the frontal } \\
\text { process of the zygomatic bone (26). } \\
\text { May be compressed by the temporalis muscle at the site } \\
\text { where the ZTN traverses the deep temporal fascia and } \\
\text { becomes superficial (12,13) = Guyuron's major migraine } \\
\text { trigger site II }(21,23,77) \# 88 ; \text { Loukas, 2008 \#80 }\end{array}$ & $\begin{array}{l}\text { In the infratemporal fossa } \\
\text { by hypertrophy or spasm of the muscles of mastication (48,57) } \\
\text { At the LPM-the ATN passes through the body of the LPM in } \\
\text { At or near the TMJ by joint inflammation or disc protrusion } \\
(46,48,76), \text { though other authors disagree (54,57) }\end{array}$ \\
\hline $\begin{array}{l}\text { By a surgical scar, often due to craniotomy (27,41-43), } \\
\text { plastic surgery (26), zygomatic fracture (26,29) or an } \\
\text { orbital disorder (33). }\end{array}$ & $\begin{array}{l}\text { At the temple (more common (6)) } \\
\text { by one or two preauricular fascial bands (15) } \\
\text { By the STA (15,77); intersects in 34\% (16) (Fig. 4) } \\
\text { It is considered a minor migraine trigger site (site V) (21) (Fig. } \\
1)\end{array}$ \\
\hline
\end{tabular}

define the "vulnerable point" (Vp), where the ZTN curves around the edge of the zygoma, as a place at which it is vulnerable to damage during surgical procedures (Fig. 5). Once it reaches the soft tissues, the ZTN runs between the bone and the temporalis muscle, then through the muscle until it pierces the temporal fascia (another potentially vulnerable point). It then divides into its terminal branches $(27,28)$ and ends in the skin, forming a plexus over the anterior temple below the superior temporal line (Fig. 6) $(12,26,27)$. A superficial branch may communicate with the ATN (12).

Highlighted anatomic variations in the pathway of the ZTN (from central to peripheral) include differences in its relationship to the inferior orbital fissure (26), the location of the ZT foramen $(13,29-32)$, the variability of branching and connections to the ATN, lacrimal and facial nerves $(12,13,27,28)$, patterns of its course within the temporalis muscle (13) and the site at which it pierces the temporal fascia $(12,13,27,28)$.

\section{Orbital Fissure:}

Hwang and colleagues (26) dissected 20 hemifaces from Korean adults, looking at the path of the ZTN. They found that in 30\% of cases, the ZTN did not cross the inferior orbital fissure but rather passed posterior to the greater wing of the sphenoid. The authors did not consider this of particular clinical significance, but emphasized the importance of the FZ suture (they call it the zygomaticofrontal suture) as a landmark. Other authors (33) stressed

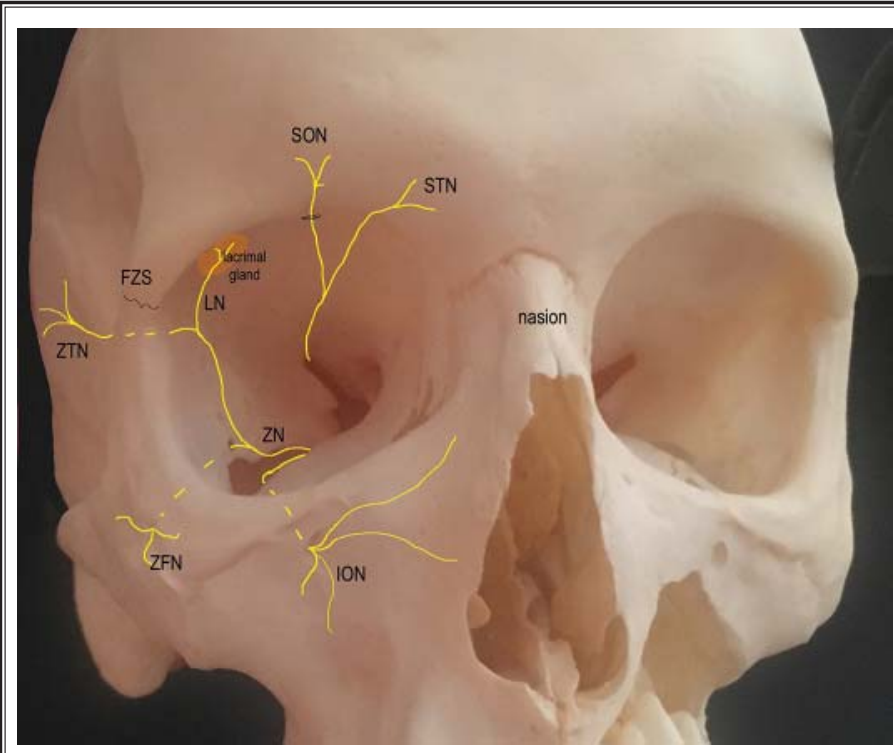

Fig. 4. Nerves of the zygoma and orbit. Note the usual relationship of the zygomatic nerve to the infraorbital fissure and the lateral wall of the orbit. SON = supraorbital nerve, traveling through the supraorbital notch; $S T N=$ supratrochlear nerve; $I O N=$ infraorbital nerve; $Z N=$ zygomatic nerve; $Z F N=$ zygomaticofacial nerve; $Z T N=$ zygomaticotemporal nerve' $L N=$ lacrimal nerve $; F Z S=$ frontozygomatic suture. (Image courtesy of Andrea Trescot, MD)

the importance of precise orbital location of the $\mathrm{ZN}$ and its branches in maxillofacial surgery, especially during treatment of zygomaticomaxillary fractures.

\section{Zygomaticotemporal Foramen}

In a study of 200 dry skulls (400 sides from adult cadavers dissected at St. George's University in Grenada, West Indies, and at Harvard Medical School in Massachusetts), Loukas et al 

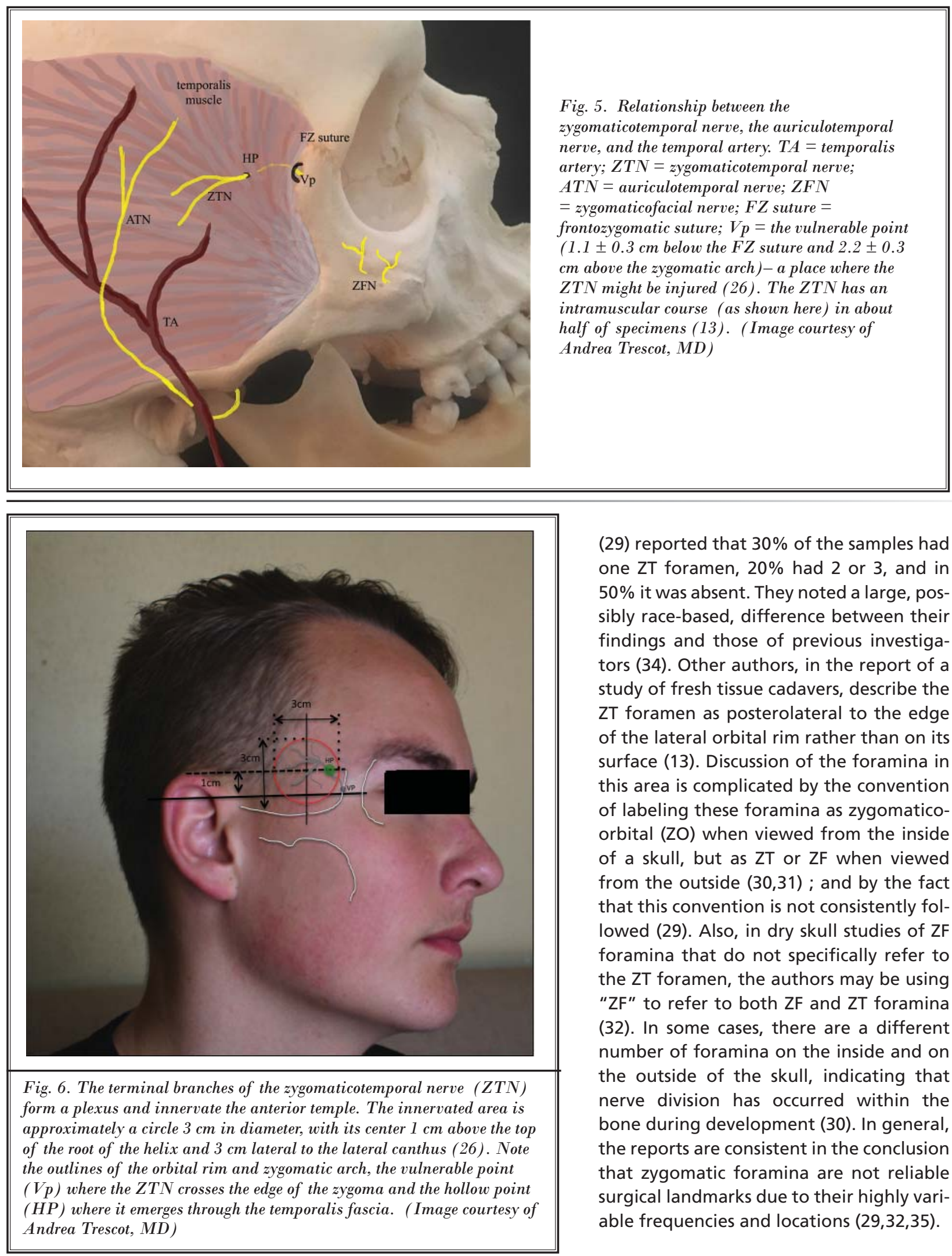

(29) reported that $30 \%$ of the samples had one ZT foramen, $20 \%$ had 2 or 3 , and in $50 \%$ it was absent. They noted a large, possibly race-based, difference between their findings and those of previous investigators (34). Other authors, in the report of a study of fresh tissue cadavers, describe the $\mathrm{ZT}$ foramen as posterolateral to the edge of the lateral orbital rim rather than on its surface (13). Discussion of the foramina in this area is complicated by the convention of labeling these foramina as zygomaticoorbital (ZO) when viewed from the inside of a skull, but as ZT or ZF when viewed from the outside $(30,31)$; and by the fact that this convention is not consistently followed (29). Also, in dry skull studies of ZF foramina that do not specifically refer to the $\mathrm{ZT}$ foramen, the authors may be using "ZF" to refer to both ZF and ZT foramina (32). In some cases, there are a different number of foramina on the inside and on the outside of the skull, indicating that nerve division has occurred within the bone during development (30). In general, the reports are consistent in the conclusion that zygomatic foramina are not reliable surgical landmarks due to their highly variable frequencies and locations $(29,32,35)$. 


\section{Connections}

Branching of the ZTN and its connections with other nerves are also variable. One study (27) reported that the ZTN was always (24/24) a single trunk with 1 to 3 terminal branches, while $(12,13,28)$ in others a single trunk was found in less than half of the specimens. This difference is likely due to differences in technique (cadaver or endoscopic studies) or definitions as to the point at which branching begins. More importantly, the presence of multiple branches to the point that the nerve was described as "arborized" in the subcutaneous tissues relatively close to the $\mathrm{ZT}$ foramen in a substantial number of specimens in one report (12/50) makes it difficult to make precise statements as to its course and connections (13). Horizontal links to the $\operatorname{ATN}(3 / 24$ or $13 \%)$ and/or lacrimal nerves $(2 / 24$ or $8.7 \%)$ were detailed in one cadaver study, (27) and described in an investigation of patients undergoing endoscopic forehead surgery (12). Facial nerve connections were not seen in one study, (27) but are mentioned in others (36-38).

\section{Temporalis Muscle}

The relationship of the ZTN to the temporalis muscle is likewise variable, though specifically investigated in only 1 study. The authors report that in $22 \%$ of the specimens (11/50), the ZTN had a short intramuscular course and in $28 \%$ of the specimens (14/50), it had a tortuous intramuscular path. In the other half of the specimens, after its exit from the ZT foramen, the ZTN passed between the bone and periosteum, and then pierced the periosteum directly into the fat pad of the temporal fascia without entering the muscle (13).

\section{Temporalis Fascia}

The place at which the ZTN pierces the deep temporal fascia is sited by one group as on average $2.2 \mathrm{~cm}(1.5-2.7 \mathrm{~cm})$ above the superior border of the zygomatic arch and $1 \mathrm{~cm}(0.7-1.3 \mathrm{~cm})$ posterior to the FZ suture (28), and by another as $1.7 \mathrm{~cm}(1.2-3.1 \mathrm{~cm})$ lateral to and $0.6 \mathrm{~cm}(0.4-1.1 \mathrm{~cm})$ cephalad to the lateral palpebral commissure (often called the lateral canthus) (12). In both of these reports, "deep temporal fascia" probably refers to the superficial layer of the temporal fascia (Fig. 2) (24). The authors describe a palpable "hollow area" at this point (12). A third group measured the intersection between the nerve and the superficial temporal fascia as $2.3 \mathrm{~cm}(1.9-2.6 \mathrm{~cm})$ above the superior border of the zygomatic arch, at the level of the pterion (27). Given that in neurosurgery the term "superficial fascia" usually refers to the superficial layer of the temporal fascia (24), all 3 groups are likely talking about the same point.

\section{Entrapment of the Zygomaticotemporal Nerve}

Few papers specifically report isolated ZTN entrapment (39). It has been described as vulnerable to injury in the orbit $(29,33)$, at the point where it crosses or curves around the edge of the zygoma, (26) and more peripherally where it could be entrapped in a scar after repair of a zygomatic fracture $(26,29)$, plastic surgery in the area (26) or craniotomy (40-43). Most commonly, ZTN entrapment is discussed in the context of migraine headaches centered on the temple $(12,13)$, and has been designated Guyuron's major migraine trigger site II (Fig. 1) $(21,23)$. Its course through and near the temporalis muscle and its fascia makes the ZTN vulnerable to temporalis hypertrophy due to bruxism or the tissue edema resulting from the hormonal changes of pregnancy or menstruation $(6,44,45)$.

\section{Anatomy of the Auriculotemporal Nerve}

The ATN is a major terminal branch of the mandibular (V3) division of the trigeminal nerve. It has close association with 2 arteries (the middle meningeal and the superficial temporal arteries), the major muscles of mastication, and the temporomandibular joint (TMJ) (46-48). It ends in the skin over the high posterior temple (Fig. 5) $(15,16)$.

The mandibular division of the trigeminal nerve (V3) crosses from the skull via the foramen ovale to the soft tissues of the infratemporal fossa, deep (medial) to the lateral pterygoid muscle (LPM) $(49,50)$. It immediately splits into a posterior division (ATN, inferior alveolar and lingual nerves) and an anterior division (buccal, deep temporal, and masseteric nerves). The 2 roots of the ATN leave the posterior aspect of the mandibular nerve, just distal to where it divides (Fig. 7). These roots surround the middle meningeal artery, and then converge within the upper part of the parotid gland to form a short $(\sim 6 \mathrm{~mm})$ trunk from which 6 named branches (the superficial temporal ramus, 2 nerves to the external acoustic meatus, the anterior auricular nerve, and 2 communicating branches to the facial nerve) separate almost immediately (51). This separation occurs at the posterior medial border of the mandibular condyle just below the external auditory meatus. The main branch (the superficial temporal ramus) runs laterally, very close to the medial capsule of the temporomandibular 


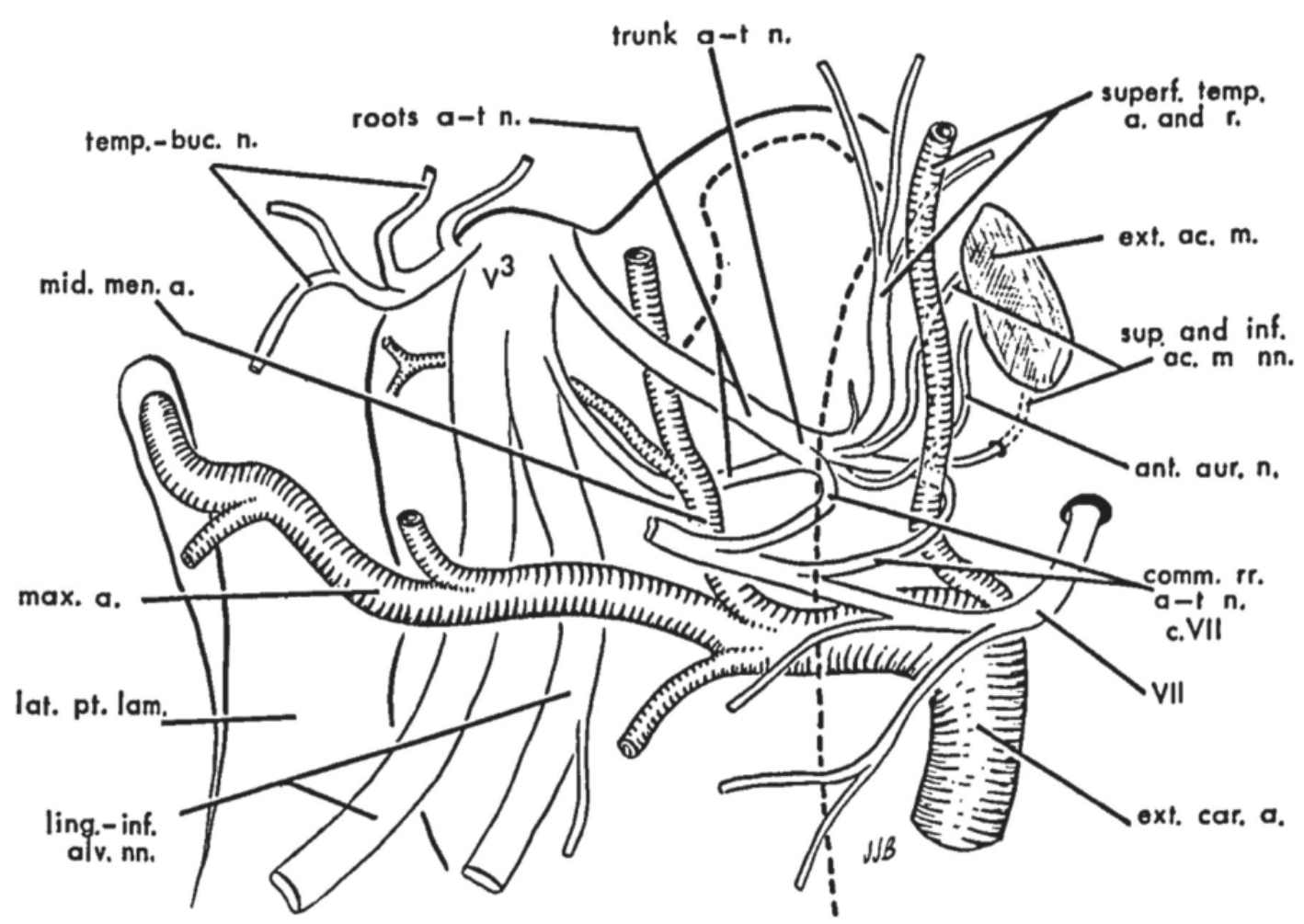

ac $\mathbf{m} \mathrm{nn}$ - nerves to external acoustic meatus a-t $\mathbf{n}$ - auriculotemporal nerve ant aur $\mathbf{n}$ - anterior auricular nerve comm rr a-t n e VII - communicating rami auriculotemporal nerve with facial nerve deep aur a - deep auricular artery ext ac $\mathrm{m}$ - external acoustic meatus ext car a - external carotid artery head mand - head of mandible lat pt lam - lateral pterygoid lamina ling-inf alv nn - lingual and inferior alveolar nerves
max a - maxillary artery
mid men a - middle meningeal artery p - parotid rami ramus mand - ramus of mandible sup and inf ac $\mathrm{m} \mathrm{nn} \mathrm{-} \mathrm{superior} \mathrm{and} \mathrm{inferior}$ nerves to external acoustic meatus superf temp a and $\mathbf{r}$ - superficial temporal
artery and ramus temp buc $\mathbf{n}$ - temporobuccal branches of the mandibular nerve $\mathbf{V}^{3}$ - mandibular nerve; VII - facial nerve

Fig. 7. Typical auriculotemporal nerve location, left side, lateral aspect. Note the following features that characterize the "average" auriculotemporal nerve: two roots with the upper root being larger and located lateral to the middle meningeal artery and the lower root being smaller and medial to the artery; a wide, open, V-shaped interval between the roots; long roots; a short trunk which breaks up abruptly into a spray of branches, usually in line with the posterior border of the mandible; the superficial temporal artery separates the anterior and posterior communicating rami with the facial nerve from one another; a terminal spray usually has six, distinct, named branches. The dashed line represents the head and posterior border of the mandible. Following contemporary custom, we term the superficial temporal ramus the auriculotemporal nerve (ATN). Baumel JJ, Vanderheiden JP, McElenney JE. The auriculotemporal nerve of man. Am J Anat. 1971;130 (4):431-440 (49). With permission

joint (TMJ) and gives off some sensory shoots to the joint $(46,48,52-54)$. Multiple small branches communicate with the facial nerve; together they are known as the central communicating branches to the facial nerve (CATNs). Taken together, the cross-sectional area of the CATNs is equal to or greater than that of the superficial 
temporal ramus $(51,55)$. Following the most common custom, we will call this superficial temporal ramus the ATN. The ATN then loops below the posterior part of the zygomatic arch and becomes progressively more superficial. It travels within the temporoparietal fascia near (and is often directly related to) the superficial temporal artery (STA) $0.8-2 \mathrm{~cm}$ anterior to the upper origin (root) of the ear helix (56) to terminate in the subcutaneous tissue of the temple (Fig. 5), roughly at the site of tenderness for many patients with pain in the temple (Fig. 1, site V) (16). Superficial branches of the ATN sometimes communicate with the ZTN, (12) the facial nerve, the lesser occipital nerve, and the greater occipital nerve (56).

The ATN carries sensory information from the TMJ (which is also innervated by the deep temporal nerve and the masseteric nerve), the parotid gland, the external acoustic canal, the tympanic membrane, the superior auricle, and the skin over the posterior superior temple. It has no motor function, but it does carry the post-ganglionic parasympathetic fibers that terminate in the parotid gland to increase saliva production (57). These parasympathetic fibers originate in the inferior salivatory nucleus, leave the glossopharyngeal nerve as part of the tympanic nerve, synapse in the otic ganglion, and join the ATN. In addition, the ATN provides sympathetic innervation to the scalp and face: post-ganglionic fibers from the superior cervical ganglion travel to the parotid and sweat glands and cutaneous blood vessels via the ATN and its branches (16).

Reported anatomic variations of note in the course of the ATN (from central to peripheral) are the number of roots $(48,51)$, the relationships to the middle meningeal artery $(51,54)$, the communication with the inferior alveolar nerve (IAN) $(51,58,59)$, the association with other structures in the infratemporal fossa $(57,60)$, the relationship to the TMJ $(46,52)$, the communications with the facial nerve $(38,51,54-56,61-63)$, as well as the incidence and type of interactions with the STA $(15,16)$. Additional confusion results from differences in naming conventions. For instance, some groups might classify a particular structure as a root $(48,59,64)$, while others call it a branch $(65,66)$.

\section{Roots}

The classic description is that the ATN is formed by 2 roots from the posterior aspect of the mandibular nerve (51). However, variable patterns from 1 to 5 roots have been reported, with 2 roots seen in $31-72 \%$ of the dissections $(48,54,59,67,68)$. Anatomic variations in the relationship of the ATN to the middle meningeal artery are closely related to the number and pattern of its roots $(51,54)$. The ATN has been reported to have connections to the IAN in $10-30 \%(48,58,59)$. The intricate root system of the ATN can provide explanations for unexpected symptom patterns $(58,59,69)$ or responses to IAN block (70).

\section{Muscles of Mastication}

The infratemporal fossa is almost entirely filled with at least parts of the 4 muscles of mastication (the LPM, medial pterygoid muscle, masseter muscle and temporalis muscle), so hypertrophy of these muscles can compress the ATN (48). Of these, the LPM is of particular interest because of its close proximity to the mandibular nerve and the ATN. The LPM (sometimes called the external pterygoid muscle) has superior and inferior parts and assists in opening the mouth $(46,57,66,71,72)$. It runs between the greater wing of the sphenoid bone and the articular disc of the TMJ (superior part) and between the pterygoid process of the sphenoid and the mandibular condyle (inferior part). The posterior division of the mandibular nerve, $(57,69,72)$ the lingual nerve (69) as well as ATN "roots" (48) and "branches" (66) are very close to and sometimes (on average about $5 \%$ of the time) pierce the LPM.

The pterygoalar ligament is another occupant of the crowded infratemporal fossa. It is a band of connective tissue between the lateral pterygoid lamina and the greater wing of the sphenoid bone, lateral to or directly below the foramen ovale. With age, this ligament can ossify into a partial or complete bar (in 2 - 32\%, depending on the population examined) and potentially impinge on the mandibular nerve and/or the ATN (60).

\section{Temporomandibular Joint}

The TMJ is very mobile, with movement in many directions, and is a common source of pain. The ATN runs just adjacent to the medial surface of the TMJ capsule $(46,48,52,53)$. Variable reports exist about the distance between the ATN and the joint, an important measurement with respect to the possibility of ATN injury due to TMJ dysfunction or inflammation. The nerve has been measured as $0-1 \mathrm{~cm}$ horizontal to the neck of the mandibular condyle and $0-1.3 \mathrm{~cm}$ below the superior border of its articular surface $(46,54)$. Of particular interest is the work of Johansson et al (52) who measured the relative positions of these structures with the jaw in different positions. They found that the 
ATN was at or below the attachment of the disc capsule when the jaw was in a neutral position, but moved more superiorly when the mouth was opened. Its position was also changed by displacement of the articular disc. Some additional variability in measurements of the distances between the ATN and the TMJ may be the result of small sample sizes (16 to 40 sides) and of differences in cadaver preparation and dissection approach. Some researchers used formalin-embalmed cadavers $(46,53,54)$, while others used frozen ones (52). The infratemporal fossa is difficult to access; some investigators approached it from above by removing the base of the skull $(53,54)$ and some approached from the side after detaching the zygomatic arch (46). One group removed specimens en bloc, refroze them in different jaw positions, then sliced, stained and reconstructed the nerve paths from the slices (52).

\section{Facial Nerve}

Communications with the facial nerve are reliably present, though with a variable pattern $(38,51,54-$ 56,61-63) and are the most consistent of the connections between the facial nerve and branches of the trigeminal nerve $(51,55,63)$. The facial nerve fibers to the muscles of facial expression leave the skull via the stylomastoid foramen (substantially posterior and lateral to the foramen ovale), travel anteriorly through the parotid gland, and then divide into the temporal, zygomatic, buccal, marginal mandibular, and cervical branches to innervate the superficial muscles of the face and upper neck. Deep in the parotid gland, 1 to 3 or more CATNs can be found $(51,61,62)$. These branches of the ATN pass forward from behind the neck of the mandible and join the temporal branches of the facial nerve at the posterior border of the masseter muscle. CATNs may supply proprioceptive input to the muscles of facial expression $(55,62,63)$, and could provide a pathway for re-establishment of motor function after facial nerve injury $(55,62)$. ATN dysfunction may lead to pain in the upper muscles of facial expression $(57,63)$. These connections may also provide a route for perineural tumor spread $(73,74)$.

The ATN (sometimes called the superficial temporal ramus of the ATN (51), see above) and the other terminal branches are closely associated with branches of the maxillary artery (51). The ATN usually splits into anterior and posterior divisions in front of the ear; these further ramify to supply the skin of the temple.

Superficial temporal artery: The STA is a branch of the external carotid artery closely associated with the temporoparietal fascia (the most superficial fascial layer) (Fig. 2) (24). Its pulse is felt just anterior to the external auditory meatus. The STA has been cited as a potential source of ATN entrapment (15) as well as a way to find the temporal branch of the facial nerve just anterior to the ear (24). The ATN has a complex relationship with the STA: the STA was found to have a direct interaction with the ATN in $34 \%$ (16) to $80 \%$ (15) of individuals. Some of these interactions are single crossovers of the artery over the nerve $(10 / 16=62 \%)$, some are helical spirals $(3 / 16=19 \%)$, and in some there was no interaction $(4 / 20=20 \%)(15)$. The most proximal crossover was found $10.8 \pm 1.8 \mathrm{~cm}$ lateral to the midline and $3.8 \pm 1.5 \mathrm{~cm}$ above the continuation of the horizontal line between the nasion and the lateral orbital rim (16).

\section{Entrapment of the Auriculotemporal Nerve}

The ATN can be entrapped at 2 distinct anatomic locations: in the infratemporal fossa and, perhaps more commonly, in the soft tissues of the temporal region (6). The infratemporal fossa is a complex area with relatively tight boundaries, so hypertrophy or spasm of the muscles of mastication (which in some cases may be caused by TMJ dysfunction ) (69) can compress the ATN $(48,57)$. The ATN is at particular risk for compression by the LPM: the posterior trunk of the mandibular nerve (including the ATN, IAN and lingual nerves) $(57,69)$ or the ATN itself $(48,66)$ passed through the body of the LPM in about $5 \%$ of cases. This sets up the possibility of a "double crush" phenomenon in which proximal compression of a nerve, such as from LPM spasm, intensifies symptoms of injury to that nerve at a more distal site $(16,75)$. Entrapment in the infratemporal fossa could explain persistent pain after TMJ repair, pain in the muscles of facial expression (57) and, depending on the portion of the posterior division of the mandibular nerve involved, sensory changes in the ear, tongue, chin, and/or lower lip $(46,48,57,58)$ and/or impaired salivation (48). The medial capsule of the TMJ is also located in the infratemporal fossa. Several authors $(46,48,76)$ have argued that the ATN could be injured at or near the TMJ by joint dysfunction, inflammation or disc protrusion, although other authors disagree $(53,54)$. Johansson $(52)$ emphasized the possibility of entrapment medial as well as posterior to the mandibular condyle.

More distally in the soft tissues of the high temple, ATN dysfunction is considered to be a minor migraine trigger site (Fig. 1, site V) (21). It can be entrapped by 
the superficial temporal artery $(15,16,77)$ (Fig. 5), and/or by 1 or 2 preauricular fascial bands (15). Chim et al (15) dissected 20 temples and identified 2 consistent fascial bands in the preauricular area: the inferior band (13.1 $\pm 5.9 \mathrm{~mm}$ anterior and $5.0 \pm 7.0 \mathrm{~mm}$ superior to the external auditory meatus) was present in all of the dissections, while the superior one $(11.9 \pm 6.0 \mathrm{~mm}$ anterior and $17.2 \pm 10.4 \mathrm{~mm}$ superior to the external auditory meatus) was present in $85 \%$ (17 of 20 ) of the specimens.

\section{Signs, Symptoms and History of Zygomaticotemporal Nerve Dysfunction}

Entrapment and other injuries of the ZTN have been reported to cause diffused pain over the zygomatic arch and anterior temple near the lateral canthus $(18,39)$, as well as post-craniotomy $(27)$ or migraine $(12-14,18,22)$ headaches. ZTN dysfunction-associated symptoms are usually the result of accidental or surgical maxillofacial trauma and of orbital disorders $(26,33,39,43)$.

\section{Signs, Symptoms and History of Auriculotemporal Nerve Dysfunction}

The anatomic relationships between the ATN and the muscles of mastication, the TMJ, and the surrounding vascular structures set up the potential for entrapment, so that ATN dysfunction can play a role in headaches as well as face, ear and TMJ pain. In addition to "high temple" headaches, entrapment or injury of the ATN can cause several distinct symptom constellations: auriculotemporal neuralgia (ATn) $(47,73,78-84)$, as well as the less common auriculotemporal syndrome (ATS, also called gustatory sweating, or Frey's syndrome), which is often due to aberrant regeneration of nerves injured during parotid surgery $(16,85-88)$. It may also cause TMJ neuralgia (Costen's syndrome) $(46,48,52,76,89,90)$.

ATN is a syndrome of severe, often episodic, unilateral facial pain in the temple, ear, TMJ, preauricular and parotid areas. Occurrences can be triggered by pressure over the ATN and resolved with a local anesthetic block $(47,78,79,81-84)$. This disorder may be the result of undiagnosed compression of the nerve (15) and can be treated with the injection, neurolytic, and/or surgical techniques described below.

Patients with ATS complain of sweating, flushing, and/or sensory disturbances, including pain in the ATN distribution with eating sour or spicy foods that produce strong salivary stimuli $(86,88)$. It is commonly accepted that these symptoms are due to the presence of both sympathetic (sweating) and parasympathetic (salivation) fibers in the ATN. When the nerve regenerates after being injured by surgery or infection, the parasympathetic fibers can mistakenly re-innervate sweat glands in the skin $(16,85-88)$. ATS can be diagnosed with the Minor's starch-iodine test $(86,88)$. In one study of 372 patients who had undergone unilateral parotidectomy, almost $25 \%$ of them developed ATS (91). Less than half of them were symptomatic, but those who were symptomatic considered it an unpleasant complication.

There are many causes of TMJ pain, but TMJ neuralgia (Costen's syndrome) should be considered as part of the differential diagnosis. The symptom constellation includes TMJ dysfunction associated with headaches in the temple region, ear pain, a "stuffy deaf" sensation, tinnitus, dizziness, headache, and a burning sensation of the throat, tongue, and side of the nose $(76,89,90)$. These symptoms were originally believed to be the result of either TMJ pathology or a lack of posterior teeth leading to a "mandibular over-closure" and ATN injury (see above) $(76,89)$. More recent authors $(46,48,52,92)$ have demonstrated that the ATN is often close enough to the TMJ that it could be damaged by $\mathrm{THJ}$ joint or disc dysfunction.

\section{Physical Examination}

The physical exam should be performed systematically to evaluate each possible area of pathology. Following each nerve from proximal to distal is one way to be sure that nothing is missed. Calandre et al (11)listed 2 separate areas of the temporalis muscle to explore during physical examination ("proximal/anterior" and "medium") fibers. Although the authors do not provide the data underlying their "typical" versus "atypical" division, they describe the anterior fibers as one of the "typical" trigger point sites, leaving the "medium" fibers to the "atypical" group. The "proximal/anterior fibers" are most likely the site where the ZTN crosses the temporalis muscle (Fig. 1 site II) and the "medium fibers" are probably near the ATN (Fig.1 site V).

Examination of the ZTN is relatively straightforward. Find the "hollow point" (HP) (also called the "hollow area") in the temple, about $2 \mathrm{~cm}$ lateral to and $1 \mathrm{~cm}$ above the lateral palpebral commissure, where the ZTN passes through the temporal fascia) (12). Tenderness at this site indicates the presence of ZTN irritation.

Since the LPM may be involved in ATN entrapment, it should be examined by palpation (46) [though there is some question as to this technique (93)] and by a provocative test (57), pressing on the chin and ask the 
patient to protrude the mandible. This maneuver activates the lower portion of the LPM and would increase symptoms if the posterior trunk of the mandibular nerve and/or the ATN were entrapped by the LPM. Further examination of the ATN should include examining the TMJ (placing the examining fingers over the joint as the patient opens and closes their mouth).

The most common site of ATN entrapment is at the temple. Trescot (6) described finding the ATN by placing the index finger at the apex of the equilateral triangle created by resting (for the right-sided exam) the thumb on the tragus and the middle finger on the corner of the eye (Fig. 8). The examiner should also palpate the remainder of the temporalis muscle (looking for trigger point tenderness) and the STA (to evaluate for temporal arteritis).

\section{Differential Diagnosis}

Although patients with ZTN and/or ATN dysfunction may report the presence of a generalized headache in the temple region, when they are asked specifically to point with one finger to the location of maximum discomfort they are often able to do so. Those with ZTN irritation will point more anteriorly and may have a history of craniotomy, facial plastic surgery or orbital frac- ture (Table 2). Patients with ATN-associated symptoms will point to a spot closer to the hairline or ear. Their history may include dental or TMJ problems as well as parotid or jaw surgery.

Other potential causes must also be considered (Table 3). Tests that may help distinguish ZTN and/or ATN entrapment are listed in Table 4.

\section{Identification and Treatment of Contributing Factors}

Bruxism is a common problem and can cause temporalis muscle spasms of varying severity (94). An anterior occlusion splint (which puts the front teeth together, precluding activation of the temporalis) may prevent this spasm that can contribute to ATN entrapment. A low dose, long-acting benzodiazepine such as clonazepam ( 0.25 to $0.5 \mathrm{mg}$ at night) or muscle relaxant such as tizanidine ( 2 to $4 \mathrm{mg}$ at night) has been effective in preventing the ATN irritation (6). If TMJ movements aggravate the patient's symptoms, a dental evaluation would be appropriate.

\section{Injection Techniques}

Injections of these nerves serve several purposes; they provide a diagnosis of the extracranial source of

Table 2. History and Physical Examination.

\begin{tabular}{|c|c|c|}
\hline & ZTN & ATN \\
\hline \multirow[t]{8}{*}{ Clinical history } & Temple migraine headaches $(21)$ & Preauricular migraine headaches (15) \\
\hline & Craniotomy $(27,41,115)$ & Toothache $(15,81)$ \\
\hline & Facial plastic surgery $(26)$ & TMJ pathology or trauma $(46,82,83)$ \\
\hline & Zygomatic fracture $(26,116)$ or osteotomy $(29)$ & Parotid surgery or severe inflammation (mumps) (87) \\
\hline & Orbital fracture (33) & Infant with a history of forceps-assisted delivery $(117,118)$ \\
\hline & Congenital orbital hypoplasia (33) & Neurofibromatosis (119) \\
\hline & Orbital tumor $(29,33)$ & Jaw abscess (87) \\
\hline & Orbital radiation $(33)$ & Trigeminal neuralgia (tic douloureux) $(16,87)$ \\
\hline \multirow{5}{*}{$\begin{array}{l}\text { Signs \& } \\
\text { Symptoms }\end{array}$} & Pain is more in/near the eye and anterior temple & Pain is more in/near the teeth and the temple at or behind the hairline \\
\hline & & May be throbbing due to association with the STA. \\
\hline & & May have TMJ pain with jaw movement $(52,67)$ \\
\hline & & May have pain in muscles of facial expression $(57,59)$ \\
\hline & & May have anterior ear pain and/or "stuffy deaf" sensation $(76,89)$ \\
\hline \multirow[t]{3}{*}{ Physical Exam } & $\begin{array}{l}\text { Tenderness in the anterior temporalis and/or } \\
\text { masseteric muscle (23) } \\
\text { Excessive tooth wear indicating bruxism (23) }\end{array}$ & $\begin{array}{l}\text { Tenderness in the temporalis muscle behind the hairline near the ear } \\
\text { (114) } \\
\text { Unilateral impaired salivation (67) } \\
\text { Paresthesias of the external acoustic meatus }(57,67) \\
\text { LPM provocative test (57) }\end{array}$ \\
\hline & & Numbness of lateral tongue, chin and/or lower lip (57) \\
\hline & & Doppler to look for an arterial signal at the site of the pain (114) \\
\hline
\end{tabular}


Nerve Entrapment Headaches at the Temple

Table 3. Differential diagnosis of temple and face pain.

\begin{tabular}{|l|l|}
\hline & Potential distinguishing features \\
\hline Cervicogenic Headache & Neck pain, cervical facet tenderness, occipital nerve tenderness \\
\hline Hemicrania Continua & Usually improves with carbamazepine and indomethacin \\
\hline Myofascial Pain & Palpable trigger points such as one in semispinalis cervicis or splenius cervicis (120) \\
\hline TMJ dysfunction & Pain over the TMJ \\
\hline Otitis & Otologic exam is abnormal \\
\hline Tooth pain & Dental exam is abnormal \\
\hline Atypical facial pain & Diagnosis of exclusion (everything else is negative) \\
\hline Trigeminal Neuralgia & Trigger zones \\
\hline Temporal arteritis & Systemically ill, elevated ESR \\
\hline
\end{tabular}

Table 4. Diagnostic tests.

\begin{tabular}{||l|l|l||}
\hline & \multicolumn{1}{|c|}{ ZTN } & \multicolumn{1}{|c|}{ ATN } \\
\hline Physical exam & $\begin{array}{l}\text { Tenderness over the hollow area } ~ 2 \mathrm{~cm} \\
\text { lateral to and } 1 \mathrm{~cm} \text { above the corner of the } \\
\text { eye (12) }\end{array}$ & $\begin{array}{l}\text { Tenderness over the apex of the triangle with its base between the tragus and } \\
\text { the corner of the eye (6) }\end{array}$ \\
\hline $\begin{array}{l}\text { Diagnostic } \\
\text { injection }\end{array}$ & $\begin{array}{l}\text { Resolution of pain after diagnostic } \\
\text { injection at hollow area }\end{array}$ & $\begin{array}{l}\text { Resolution of pain after diagnostic injection at distal and occasionally } \\
\text { proximal sites }\end{array}$ \\
\hline Ultrasound & $\begin{array}{l}\text { Nerve identified next to temporal artery } \\
\text { "Halo sign" in temporal arteritis (121) }\end{array}$ \\
\hline MRI & $\begin{array}{l}\text { May be identified in perineural spread of tumor between the facial nerve and } \\
\text { Z3, seen as enlargement or abnormal gadolinium enhancement of the nerves, } \\
\text { or obliteration of the perineural fat pad (73,74). }\end{array}$ \\
\hline X-ray & $\begin{array}{l}\text { May show fracture of orbit (33) or } \\
\text { zygoma (26,116) }\end{array}$ & May show fracture of mandible (90) \\
\hline
\end{tabular}

the headache, they deliver therapeutic medication to the targeted area, and they allow prediction as to whether further surgical or neurolytic treatment might offer benefit. However, the diagnosis is predicated on the patient actually getting numb from the local anesthetic used, and, if questioned, a significant number of patients will report difficulty getting numb with sutures, dental procedures, or pain procedures.

In 2003, Trescot (95) described a skin test to determine the most effective local anesthetic to use on an individual patient. Of nearly 1,200 patients interviewed, 250 had a history of difficulty getting numb. Of those, 90 only lost sensation after testing with mepivicaine, a local anesthetic not often used in clinical practice; an additional 43 only responded to lidocaine. Although this was only $11 \%$ of the total group, it was $53 \%$ of the patients with a history of "local anesthetic resistance". Consideration might therefore be given to skin testing patients prior to injections.

The injections can be done purely for diagnosis with just local anesthetic, or local anesthetic and a deposteroid can be mixed together and injected. Total volumes injected here should be small (less than $1 \mathrm{~mL}$ ); because methylprednisolone is available in a high concentration $(80 \mathrm{mg} / \mathrm{mL})$, it is therefore the medication of choice for one author (AT). Because the skin is thin in this area, there is a significant risk of steroid-induced atrophy, and so steroid dose should be less than $40 \mathrm{mg}$ of methylprednisolone equivalents. Small gauge needles ( 27 to 30 gauge) are used both for patient comfort and to avoid inadvertent injury to the nerves; a $3 \mathrm{~mL}$ syringe is used for ease of injection.

\section{Injection Technique for ZTN}

\section{Landmark-Guided Technique}

ZTN injections are performed at the site at which the nerve pierces the deep temporal fascia $(12,13)$. Palpate the hollow exit area approximately $1.5 \mathrm{~cm}$ lateral to and $0.5 \mathrm{~cm}$ above the lateral palpebral commissure and insert a 1-inch 27- to 30-gauge needle approximately $1 \mathrm{~cm}$ posterolateral to and in the direction of 

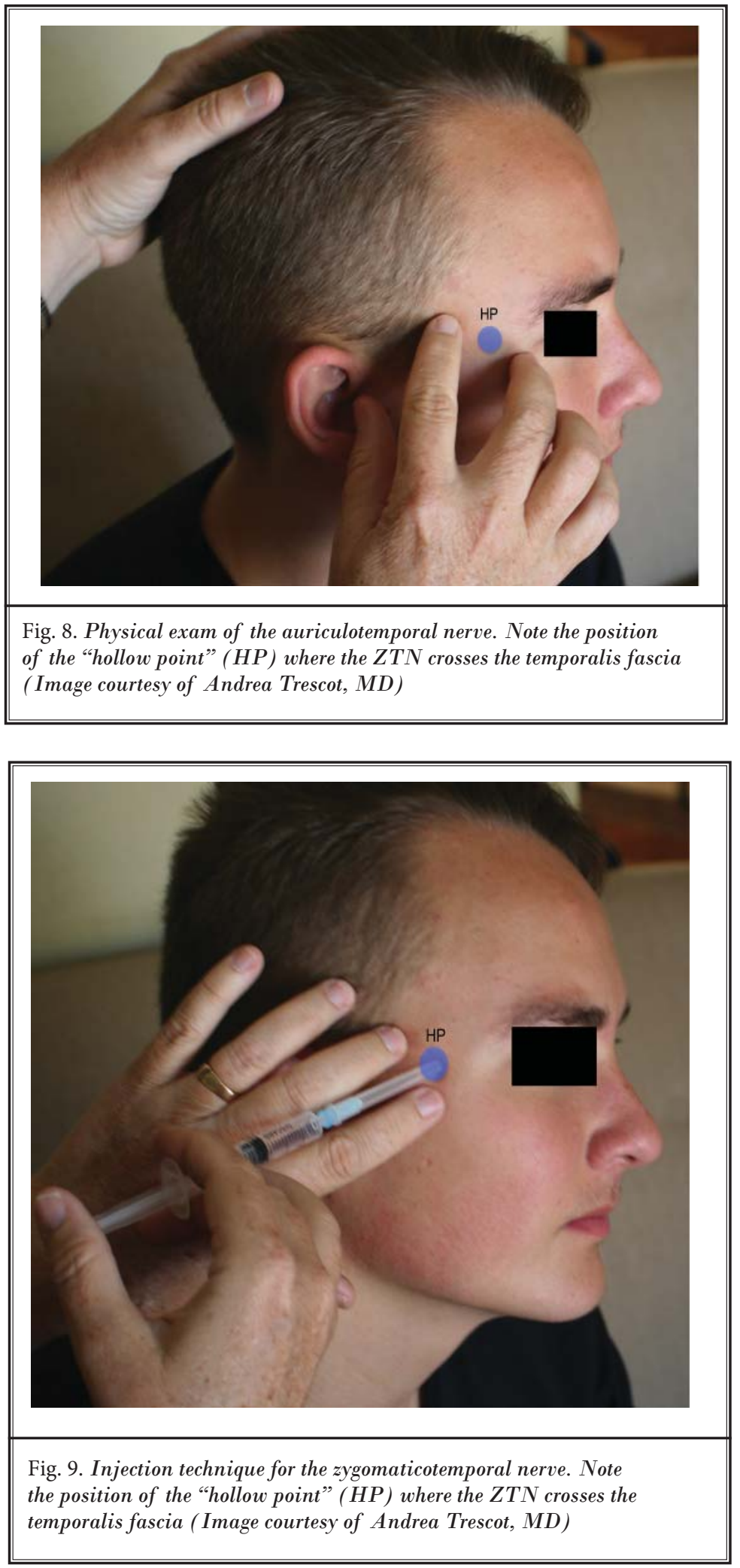

the hollow point (Fig 9). Note the increase in resistance as the needle crosses the deep temporal fascia (12); be careful not to inject more than about 0.5 to $0.75 \mathrm{~mL}$ in this area, because of the small space.

\section{Injection Technique for ATN}

\section{Landmark-Guided Technique}

The distal ATN injection is more commonly used. Identify the tender area at the apex of a triangle with a base composed of the line connecting the tragus and the corner of the eye (Fig. 8) (6), typically $1-2 \mathrm{~cm}$ anterior to the root of the ear helix $(56,96)$. This site is usually very close to the artery; confirm that the artery itself is not tender to decrease the likelihood of a missed diagnosis of temporal arteritis. Inject one $\mathrm{mL}$ of local anesthetic and depo-steroid in a slightly cephalad direction, parallel to the path of the nerve (Fig. 10-A). The artery is usually marginally more posterior; if arterial pulsations are not obvious, place the injection slightly anteriorly to avoid a hematoma. Take care to avoid injecting directly into the artery, especially with particulate steroids, to avoid a potential embolization (which has never been reported).

Proximal (less common) landmarkguided ATN injections are performed where the nerve passes the posterior aspect of the mandibular condyle, slightly below the zygoma. Insert a 3.5-inch, 27-gauge needle anterior to the junction of the tragus and the lobule (Fig. 10-B). Withdraw the needle 3-5 $\mathrm{mm}$ so as to avoid an intracapsular TMJ injection $(47,97,98)$. This site is close to the facial nerve, and the patient must be warned of the possibility of temporary facial nerve weakness. For that reason (and because the region is very vascular) small volumes $(0.5 \mathrm{~mL})$ and meticulous needle placement are recommended. If temporary facial nerve palsy occurs, tape the eyelid closed, thenpatch the eye until the local anesthetic has worn off.

Speciali and Gonçalves (47) reported a series of 6 patients with ATN. They injected 


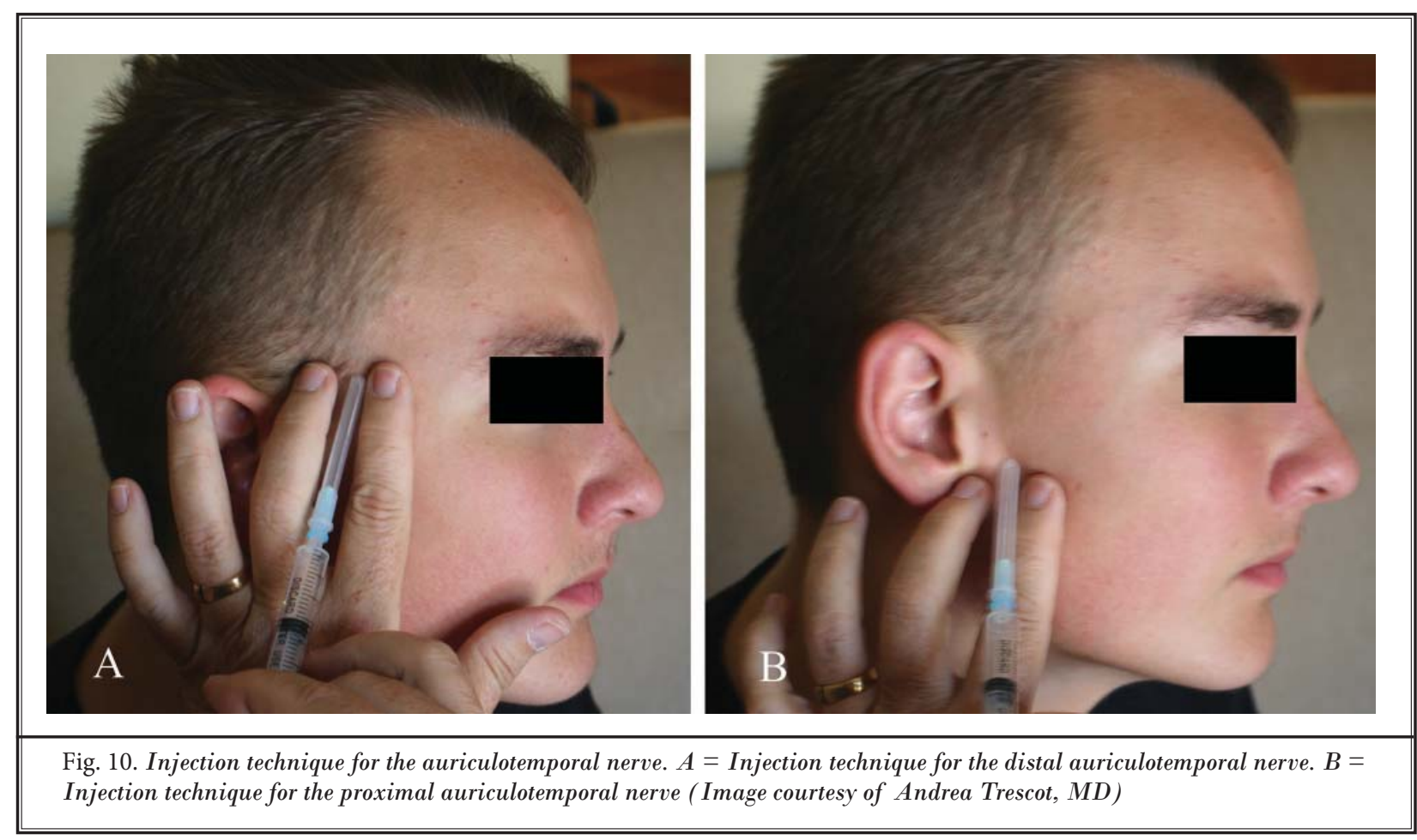

the proximal ATN using $0.5 \mathrm{~mL}$ of $2 \%$ lidocaine with dexamethasone $2.5 \mathrm{mg}$ (up to $1.5 \mathrm{~mL}$ ). Only one patient had recurrence of pain after a single injection, but the authors report a short follow-up of less than 1 year.

There is occasionally a "double crush" syndrome of the ATN, with the nerve trapped at both the proximal and distal sites. These patients describe persistent temple pain after injection of the distal ATN, with tenderness anterior to the tragus. The proximal site would then need to be treated.

\section{Fluoroscopy}

There are no bony landmarks for fluoroscopy to be useful.

\section{Ultrasound-guided Technique}

Several authors $(99,100)$ have described an ultrasound (US)-guided technique for distal ATN injection. Place the probe transversely just above the TMJ, and identify the STA with color Doppler. The ATN is a small hypoechoic structure next to the superficial temporal artery (Fig. 11-A). Rotate the probe for a longitudinal scan to track the nerve cephalad (Fig.11-B). The authors used a 25-gauge needle from an out-of-plane approach to deliver $2 \mathrm{~mL}$ of $1 \%$ lidocaine and $10 \mathrm{mg}$ of DepoMedrol $\circledast$ around the nerve. This selective targeting provided symptom relief for a patient with an injuryrelated unilateral headache who had failed to respond to less specific injections (99).

\section{Neurolytic and Surgical Techniques}

\section{Chemical Neurolysis}

Chemical neurolytic techniques involve the use of botulinum toxin, alcohol or phenol. Botulinum toxin is commonly injected into the temporalis muscle to diagnose and/or treat parieto-temporal migraines, which presumably results in decreased entrapment of the ZTN $(12,13)$.

Because of the potential spread of medication, alcohol or phenol is not recommended, except in special cases such as the treatment of cancer pain.

\section{Surgery}

Over the last 15 years, surgical treatment of patients with severe chronic migraine headaches has been well established on the basis of retrospective reviews $(3,14)$, a pilot study (101), a prospective randomized clinical trial (19), a long-term outcome study (21), and demonstration of its cost-effectiveness (102). Initially, surgery was reserved for patients whose symptoms responded to diagnostic local anesthetic and/or botu- 


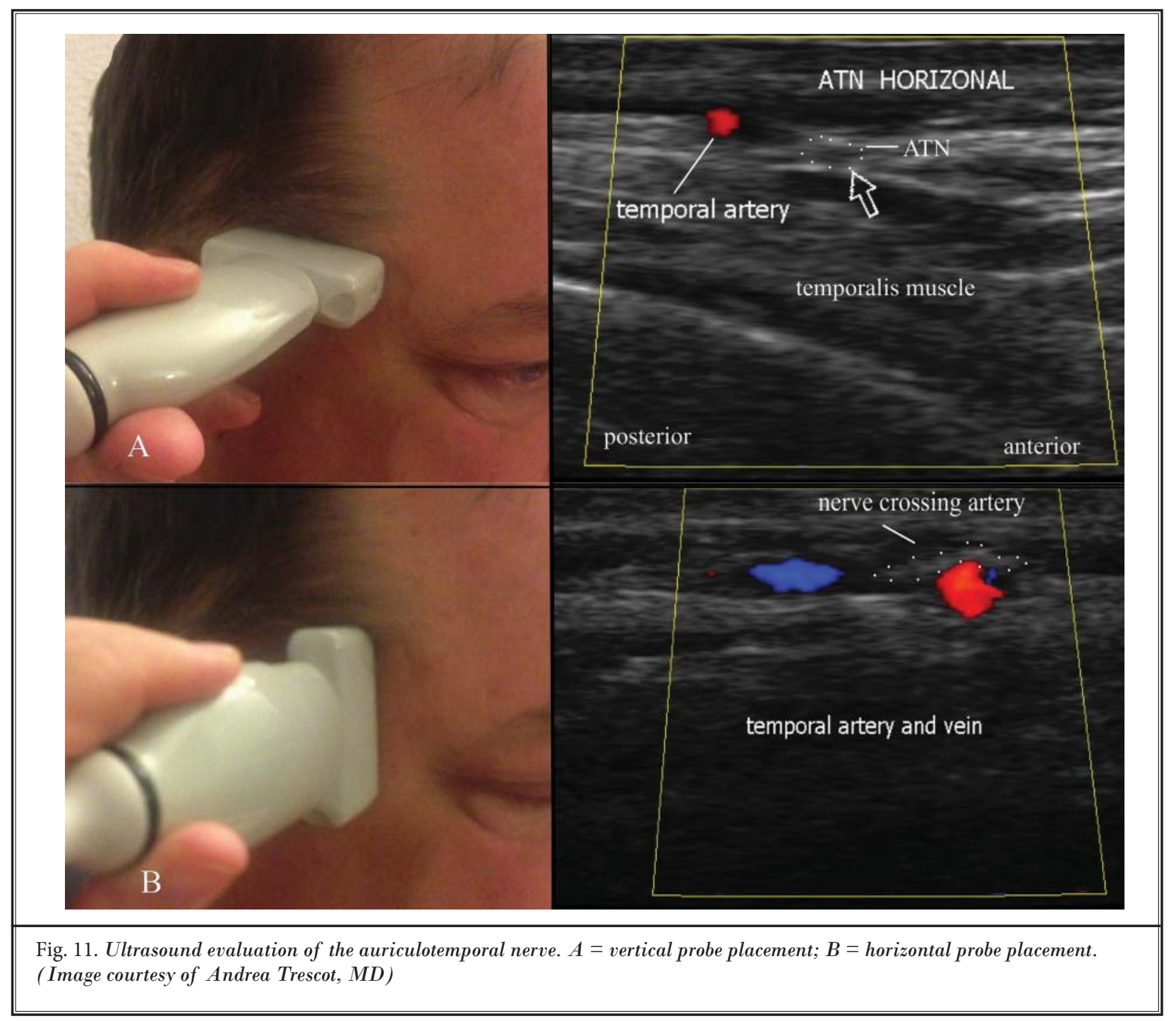

linum toxin injections $(14,20,101)$, although with more experience some have omitted this step (103).

Surgical treatment of migraine headaches is not without controversy, and further careful investigation of this matter is warranted (104-106).

\section{Neurolytic/Surgical Techniques for ZTN Dysfunction and their Potential Complications}

\section{Chemical Neurolysis}

Dilute 12.5 to 25 units of botulinum toxin in $0.5 \mathrm{~mL}$ of saline in a $3 \mathrm{~mL}$ syringe, and attach a 1 -inch 30-gauge needle. Palpate the hollow point area (HP), approximately $1.5 \mathrm{~cm}$ lateral to and $0.5 \mathrm{~cm}$ above the lateral palpebral commissure, and insert the needle approximately $2 \mathrm{~cm}$ posterolateral to and in the direction of the HP. Note the increase in resistance as the needle crosses the deep temporal fascia. Inject some of the botulinum toxin into the temporalis muscle at this point then direct further injections cephalad, posteriorly and caudally to paralyze the muscle fibers immediately next to the ZTN $(12)$. These $(107,108)$ authors assert that the toxin will diffuse in a circle with a radius of approximately $1.5 \mathrm{~cm}$.

Complications reported after ZTN landmarkguided botulinum toxin injections include diplopia (13) and decreased strength of mandibular closure (12). Diplopia is a debilitating, though rare, complication that is thought to be due to diffusion of botulinum 
toxin through the $\mathrm{ZT}$ foramen, weakening the nearby lateral rectus muscle. The authors recommend a relatively superficial injection into the temporalis muscle, well lateral to the orbital rim (13).

\section{Surgery}

The hollow point (HP), recognized as the exit point of the ZTN through the deep temporal fascia (on average $1.7 \mathrm{~cm}$ lateral and $0.6 \mathrm{~cm}$ cephalad of the lateral palpebral commissure), allows identification of the surgical site in individual patients (12). In the traditional surgical avulsion method, about $3 \mathrm{~cm}$ of the intramuscular portion of the ZTN is removed and the proximal end retracts into the orbit; this is a common occurrence in procedures done in this area for other reasons $(12,109)$. Recently, Guyuron and colleagues reported the results of a prospective randomized clinical trial to evaluate 2 endoscopic surgical techniques for treatment of temporal migraine headaches (103). Due to the fact that neuromas have occurred after avulsion of other nerves and that surgeons and patients consider avulsion more invasive than decompression, they randomized 19 patients with severe bilateral temporal migraine headaches to have traditional avulsion of the ZTN on one side and decompression by fasciotomy and cauterization of the accompanying blood vessels on the other. At 1 year, they found a dramatic reduction in frequency, migraine days, severity and duration in $89 \%$ of operative sites (34/38), with complete elimination in $55 \%$. On average, patients' headaches decreased from 14 to 2 per month. No patient had a complication and there was no difference in outcome measures between the 2 groups. The authors recommend decompression as the preferred first option, and offer avulsion neurectomy to the few patients whose decompression sites achieve less than $50 \%$ relief.

In addition to endoscopic approaches to the ZTN $(12,103)$, a case series (20) describing an open procedure with an incision just posterior to the temporal hairline has been reported. The authors investigated the open technique because substantial experience is required to become proficient at endoscopy, long instruments are used to manipulate these very fine nerves, and endoscopic techniques require extensive dissection, especially when the procedure is performed bilaterally. The authors assessed the ZTN for viability and decompressed it as described above (although they label the blood vessel accompanying the ZTN through the fascia as "a sentinel vein" rather than an artery). If the nerve was not thought to be viable, they transected it and buried the end deep in the temporalis muscle. Some patients also had ATN decompression through the same incision. After one year, they found that $84 \%(16 / 19)$ of patients had at least $50 \%$ reduction in symptoms and $37 \%(7 / 19)$ had no further headaches in the temple region. There was no difference in outcome between the 2 groups. The authors hope that this simpler technique will "lower the bar" to adoption of surgical treatment of temple migraine headaches.

\section{Neurolytic/Surgical Techniques for ATN Dysfunction and their Potential Complications}

\section{Chemical Neurolysis}

Intracutaneous botulinum toxin has been used to treat ATS (Frey's Syndrome) (110). Since this site is very close to the path of the facial nerve in the parotid gland, there is at least a theoretic risk of facial nerve paresis from the toxin.

\section{Cryoneuroablation}

Cryoneuroablation has been an effective therapeutic technique for ATn. Trescot $(5,6)$ described the use of cryoneuroablation for the treatment of extracranial headache syndromes including ATN entrapment. The cryo probe is placed parallel to the nerve and, using sensory stimulation, the probe is swept side to side to find the nerve.

\section{Peripheral Nerve Stimulation}

Until recently, peripheral stimulation of the ATN has been limited by technical considerations, but recent advances have increased their use (96). In 2010, Simopoulos and colleagues (111)described bilateral ATN stimulation; the next year Deshpande and Wininger (112)described a combined stimulation of the ATN and the greater occipital and lesser occipital nerves (Fig. 12).

\section{Surgery}

A 5-year randomized study of 69 migraine patients comparing surgery to botulinum toxin of "migraine trigger points" (including the ATN area) showed an $88 \%$ improvement in headaches after surgical release (21). Some authors (18) emphasize the importance of intraoperative Doppler monitoring to identify the precise location of the STA so as to minimize dissection trauma. Endoscopic ATN surgery was pioneered by Guyuron (101) and expanded by Sanniec (18). This procedure is easily combined with ZTN decompression due 


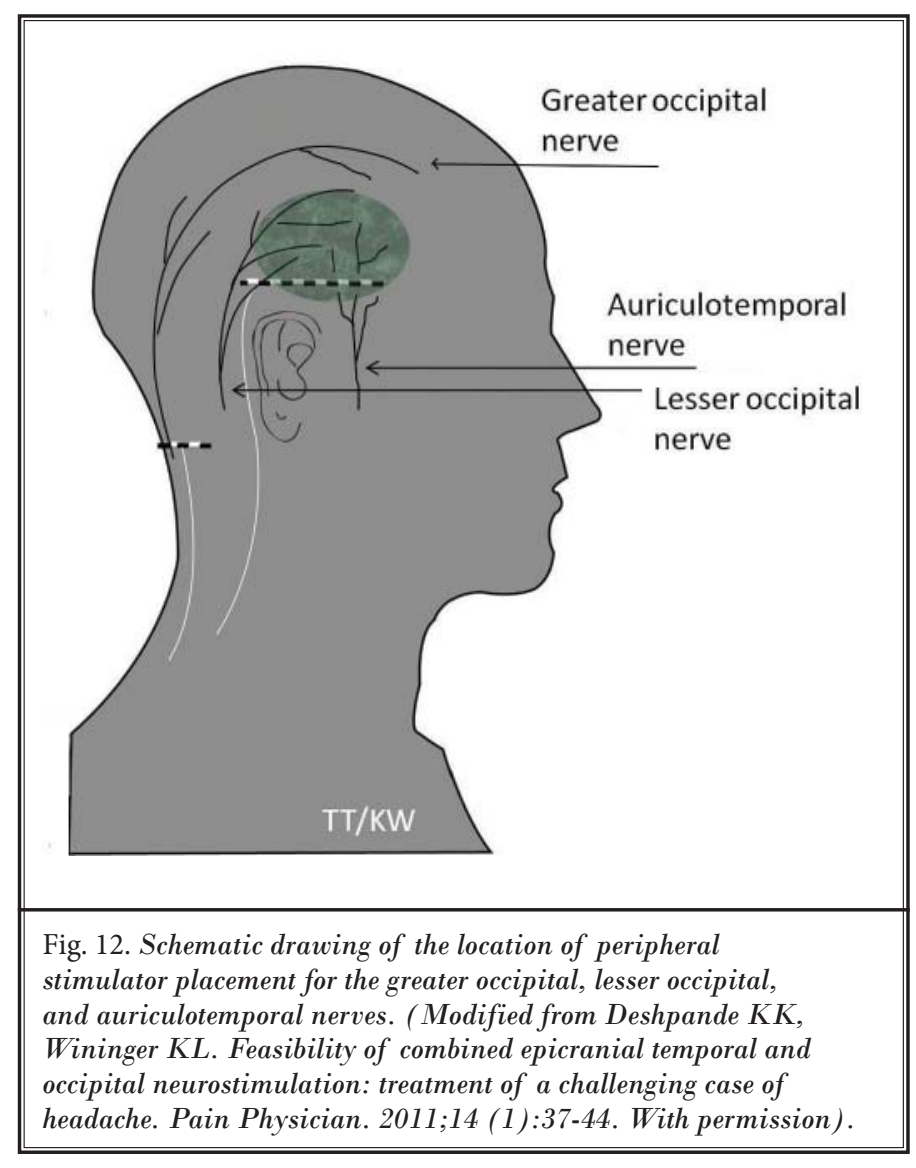

to the close proximity of the 2 nerves at the temple. In order to avoid injury to the temporal branch of the facial nerve, the authors recommend releasing the main branch of the ATN just above the TMJ.

\section{Discussion}

Headaches, including migraine headaches, are common, disabling and expensive. Recent work on the role of injuries to and sensitization of peripheral nerves as a trigger for migraine headaches has provided new hope for patients and spurred research into anatomic understanding of the anatomy of the nerves involved. Based on the dramatic and often complete relief of "migraines" with injections of these nerves, these extracranial nerve entrapments may represent the actual etiology and not just the trigger of headaches that have been misdiagnosed as "intracranial". Investigation of failures of medical and surgical treatment served as a particular incentive to understand anatomic details $(13,16)$.

Some discrepancies in the descriptions of ZTN anatomy can be explained by differences in purpose and methods among the reports. For example, some authors (26) interested in bony procedures such as zygomatic fracture reduction involving the lateral orbital wall began their cadaveric dissection in the orbit after the eye and accessory visual structures had been removed. Others with a particular interest in craniotomies traced the course of the ZTN in cadavers from the periphery, past the pterion [the region where the frontal, parietal, temporal and sphenoid bones join - a common neurosurgical approach to the middle cranial fossa (113)] to the ZT foramen (27). A third group focused on surgical treatment of migraine headaches and investigated patients undergoing endoscopic forehead surgery (12) or fresh cadavers (13) and also began their anatomic explorations at the periphery.

Because symptoms of ATN dysfunction have been of long-standing interest, its anatomy is better understood, although the course of the nerve around the TMJ is still a matter for discussion $(76,85,89)$.

As is evident from reports in both the neurology (11) and neurosurgical (114) literature, it is very likely that either or both nerves can be the cause of a headache in the temple region and imply that the ZTN is involved more frequently than the ATN. Investigation into the cause of the headache in an individual patient should include systematic evaluation of both nerves.

\section{SUMMARY}

Both the ZTN and the ATN have been associated with headaches in the temple region. Dysfunction of the ZTN is likely after surgery or trauma to the orbital wall, and is associated with temple-region headaches as well as neuropathic pain and paresthesias in the area that it innervates (39). Disturbances of ATN function also cause temple-region headaches, although one-finger demonstration of the area of maximum pain at the start of the headache usually reveals a more posterior location. These patients have histories and other symptoms more related to the jaw and ear. As always, the presence of anatomic variability underlines the importance of careful physical examination and diagnostic injections before substantial further intervention in any individual patient (6). 


\section{Acknowledgments}

We would like to thank Gábor Balsa, MD, an extraordinary anatomist at Semmelweis University in Budapest, Hungary, for his beautiful dissections of the temple, which started us down this road of comparing the ATN to the ZTN. We would also like to thank Benjamin Mansfeld of Namibia, Africa, for patiently agreeing to be a model for this article.

\section{References}

1. World Health Organization Media Centre. Headache disorders: Fact sheet, 2016: $\quad$ www.who.int/mediacentre/ factsheets/fs277/en/

2. The international classification of headache disorders, 3 rd edition (beta version). Cephalalgia 2013; 33:629-808.

3. Guyuron B, Varghai A, Michelow B], Thomas T, Davis J. Corrugator supercilii muscle resection and migraine headaches. Plast Reconstr Surg 2000; 106:429-434; discussion 435-427.

4. Gobel H, Heinze A, Heinze-Kuhn K, Jost WH. Evidence-based medicine: Botulinum toxin a in migraine and tensiontype headache. J Neurol 2001; 248 Suppl 1:34-38.

5. Trescot AM. Headache management in an interventional pain practice. Pain Physician 2000; 3:197-200.

6. Trescot AM. Headache: Is it a migraine? Think again. Technol Reg Anesth Pain Manag 2005; 9:68-72.

7. Dalkara T, Zervas NT, Moskowitz MA. From spreading depression to the trigeminovascular system. Neurol Sci 2006; 27 Suppl 2:S86-90.

8. Moskowitz MA. Defining a pathway to discovery from bench to bedside: The trigeminovascular system and sensitization. Headache 2008; 48:688-69o.

9. Karatas H, Erdener SE, Gursoy-Ozdemir Y, Lule S, Eren-Kocak E, Sen ZD, Dalkara T. Spreading depression triggers headache by activating neuronal panxi channels. Science 2013; 339:1092-1095.

10. Guyuron B, Yohannes E, Miller R, Chim $H$, Reed D, Chance MR. Electron microscopic and proteomic comparison of terminal branches of the trigeminal nerve in patients with and without migraine headaches. Plast Reconstr Surg 2014; 134:796e-805e.

11. Calandre EP, Hidalgo J, Garcia-Leiva JM, Rico-Villademoros F. Trigger point evaluation in migraine patients: An indication of peripheral sensitization linked to migraine predisposition? Eur ] Neurol 2006; 13:244-249.

12. Totonchi A, Pashmini N, Guyuron B.
The zygomaticotemporal branch of the trigeminal nerve: An anatomical study. Plast Reconstr Surg 2005; 115:273-277.

13. Janis JE, Hatef DA, Thakar H, Reece EM, McCluskey PD, Schaub TA, Theivagt C, Guyuron B. The zygomaticotemporal branch of the trigeminal nerve: Part ii. Anatomical variations. Plast Reconstr Surg 2010; 126:435-442.

14. Poggi JT, Grizzell BE, Helmer SD. Confirmation of surgical decompression to relieve migraine headaches. Plast $\mathrm{Re}$ constr Surg 2008; 122:115-122; discussion 123-114.

15. Chim H, Okada HC, Brown MS, Alleyne B, Liu MT, Zwiebel S, Guyuron B. The auriculotemporal nerve in etiology of migraine headaches: Compression points and anatomical variations. Plast Reconstr Surg 2012; 130:336-341.

16. Janis JE, Hatef DA, Ducic I, Ahmad J, Wong C, Hoxworth RE, Osborn T. Anatomy of the auriculotemporal nerve: Variations in its relationship to the superficial temporal artery and implications for the treatment of migraine headaches. Plast Reconstr Surg 2010; 125:1422-1428.

17. Kurlander DE, Punjabi A, Liu MT, Sattar A, Guyuron B. In-depth review of symptoms, triggers, and treatment of temporal migraine headaches (site ii). Plast Reconstr Surg 2014; 133:897-903.

18. Sanniec K, Borsting E, Amirlak B. Decompression-avulsion of the auriculotemporal nerve for treatment of migraines and chronic headaches. Plast Reconstr Surg Glob Open 2016; 4:e678.

19. Guyuron B, Reed D, Kriegler JS, Davis J, Pashmini N, Amini S. A placebo-controlled surgical trial of the treatment of migraine headaches. Plast Reconstr Surg 2009; 124:461-468.

20. Peled ZM. A novel surgical approach to chronic temporal headaches. Plast Reconstr Surg 2016; 137:1597-1600.

21. Guyuron B, Kriegler JS, Davis J, Amini $\mathrm{SB}$. Five-year outcome of surgical treatment of migraine headaches. Plast Reconstr Surg 2011; 127:603-608.

22. Janis JE, Dhanik A, Howard JH. Vali- dation of the peripheral trigger point theory of migraine headaches: Singlesurgeon experience using botulinum toxin and surgical decompression. Plast Reconstr Surg 2011; 128:123-131.

23. Liu MT, Armijo BS, Guyuron B. A comparison of outcome of surgical treatment of migraine headaches using a constellation of symptoms versus botulinum toxin type a to identify the trigger sites. Plast Reconstr Surg 2012; 129:413-419.

24. Davidge KM, van Furth WR, Agur A, Cusimano M. Naming the soft tissue layers of the temporoparietal region: Unifying anatomic terminology across surgical disciplines. Neurosurgery 2010; 67: ons120-129; discussion ons129-130.

25. Schuenke M, Schulte E, Schumacher U. Thieme Atlas of Anatomy: Head and Neuroanatomy, Ist edition,. (eds. Scheunke M, Schulte E, Schumacher U, Ross LM, Lampert ED) Thieme, Stuttgart, Germany 2010.

26. Hwang K, Suh MS, Lee SI, Chung IH. Zygomaticotemporal nerve passage in the orbit and temporal area. J Craniofac Surg 2004; 15:209-214.

27. Tubbs RS, Mortazavi MM, Shoja MM, Loukas M, Cohen-Gadol AA. The zygomaticotemporal nerve and its relevance to neurosurgery. World Neurosurg 2012; 78:515-518.

28. Jeong SM, Park KJ, Kang SH, Shin HW, Kim H, Lee HK, Chung YG. Anatomical consideration of the anterior and lateral cutaneous nerves in the scalp. J Korean Med Sci 2010; 25:517-522.

29. Loukas M, Owens DG, Tubbs RS, Spentzouris G, Elochukwu A, Jordan R. Zygomaticofacial, zygomaticoorbital and zygomaticotemporal foramina: Anatomical study. Anat Sci Int 2008; 83:77-82.

30. Mangal A, Choudhry R, Tuli A, Choudhry $S$, Choudhry R, Khera V. Incidence and morphological study of zygomaticofacial and zygomatico-orbital foramina in dry adult human skulls: The nonmetrical variants. Surg Radiol Anat 2004; 26:96-99. 
31. Patel P, Belinsky I, Howard D, Palu RN. Location of the zygomatico-orbital foramen on the inferolateral orbital wall: Clinical implications. Orbit 2013; 32:275-277.

32. Aksu F, Ceri NG, Arman C, Zeybek FG, Tetik S. Location and incidence of the zygomaticofacial foramen: An anatomic study. Clin Anat 2009; 22:559-562.

33. Govsa F, Celik S, Ozer MA. Orbital restoration surgery in the zygomaticotemporal and zygomaticofacial nerves and important anatomic landmarks. J Craniofac Surg 2009; 20:540-544.

34. Kim H, Paik D, Choi B, Chung M, Han $\mathrm{S}$, Hwang Y, Sohn H, Chung R, Koh K. Measurements of the zygomatic bones and morphology of the zygomaticofacial and zygomaticotemporal foramina in korean. Korean J Phys Anthropol 1997; 10:225-234.

35. Wartmann CT, Loukas M, Tubbs RS. Zygomaticofacial, zygomaticoorbital, and zygomaticotemporal foramina. Clin Anat 2009; 22:637-638.

36. Shimada K, Moriyama H, Ikeda M, Tomita $\mathrm{H}$, Shigihara S, Gasser RF. Peripheral communication of the facial nerve at the angle of the mouth. Eur Arch Otorhinolaryngol 1994:S110-112.

37. Odobescu A, Williams HB, Gilardino MS. Description of a communication between the facial and zygomaticotemporal nerves.] Plast Reconstr Aesthet Surg 2012; 65:1188-1192.

38. Hwang K, Yang SC, Song JS. Communications between the trigeminal nerve and the facial nerve in the face: A systematic review. J Craniofac Surg 2015; 26:1643-1646.

39. Ramirez OM, Pozner JN. Endoscopicassisted wire removal and neurolysis. Ann Plast Surg 1996; 37:184-186.

40. Tubbs RS, Hill M, May WR, Middlebrooks E, Kominek SZ, Marchase N, Shoja MM, Loukas M, Oakes WJ. Does the maxillary division of the trigeminal nerve traverse the cavernous sinus? An anatomical study and review of the literature. Surg Radiol Anat 2008; 30:37-40.

41. Rocha-Filho PA, Gherpelli JL, de Siqueira JT, Rabello GD. Post-craniotomy headache: Characteristics, behaviour and effect on quality of life in patients operated for treatment of supratentorial intracranial aneurysms. Cephalalgia 2008; 28:41-48.

42. Rocha-Filho P, Gherpelli J, de Siqueira J, Rabello G. Post-craniotomy headache: A proposed revision of ihs diagnostic criteria. Cephalalgia 2010; 30:560-566

43. Rocha-Filho PA. Post-craniotomy headache: A clinical view with a focus on the persistent form. Headache 2015; 55:733-738.

44. White CP, Hitchcock CL, Vigna YM, Prior JC. Fluid retention over the menstrual cycle: 1-year data from the prospective ovulation cohort. Obstet Gynecol Int 2011; 2011:138451.

45. Massey EW. Menstrual meralgia. Arch Neurol 1978; 35:549.

46. Schmidt BL, Pogrel MA, Necoechea M Kearns $G$. The distribution of the auriculotemporal nerve around the temporomandibular joint. Oral Surg Oral Med Oral Pathol Oral Radiol Endod 1998; 86:165-168

47. Speciali JG, Goncalves DA. Auriculotemporal neuralgia. Curr Pain Headache Rep 2005; 9:277-280.

48. Komarnitki I, Andrzejczak-Sobocinska A, Tomczyk J, Deszczynska K, Ciszek B. Clinical anatomy of the auriculotemporal nerve in the area of the infratemporal fossa. Folia Morphol (Warsz) 2012; 71:187-193.

49. Piagkou M, Demesticha T, Skandalakis $P$, Johnson EO. Functional anatomy of the mandibular nerve: Consequences of nerve injury and entrapment. Clin Anat 2011; 24:143-150.

50. Piagkou MN, Demesticha T, Piagkos G, Androutsos G, Skandalakis P. Mandibular nerve entrapment in the infratemporal fossa. Surg Radiol Anat 2011; 33:291-299.

51. Baumel JJ, Vanderheiden JP, McElenney JE. The auriculotemporal nerve of man. Am J Anat 1971; 130:431-440.

52. Johansson AS, Isberg A, Isacsson G. A radiographic and histologic study of the topographic relations in the temporomandibular joint region: Implications for a nerve entrapment mechanism. J Oral Maxillofac Surg 1990; 48:953-961; discussion 962 .

53. Loughner BA, Gremillion HA, Mahan PE, Watson RE. The medial capsule of the human temporomandibular joint. J Oral Maxillofac Surg 1997; 55:363-369; discussion 369-370.

54. Fernandes PR, de Vasconsellos HA, Okeson JP, Bastos RL, Maia ML. The anatomical relationship between the position of the auriculotemporal nerve and mandibular condyle. Cranio 2003; 21:165-171.
55. Baumel JJ. Trigeminal-facial nerve communications. Their function in facial muscle innervation and reinnervation. Arch Otolaryngol 1974; 99:34-44.

56. Becser Andersen N, Bovim G, Sjaastad $\mathrm{O}$. The frontotemporal peripheral nerves. Topographic variations of the supraorbital, supratrochlear and auriculotemporal nerves and their possible clinical significance. Surg Radiol Anat 2001; 23:97-104

57. Loughner BA, Larkin LH, Mahan PE. Nerve entrapment in the lateral pterygoid muscle. Oral Surg Oral Med Oral Pathol 1990; 69:299-306.

58. Anil A, Peker T, Turgut HB, Gulekon IN, Liman F. Variations in the anatomy of the inferior alveolar nerve. $\mathrm{Br}$ J Oral Maxillofac Surg 2003; 41:236-239.

59. Gulekon N, Anil A, Poyraz A, Peker T, Turgut HB, Karakose M. Variations in the anatomy of the auriculotemporal nerve. Clin Anat 2005; 18:15-22.

6o. Natsis K, Piagkou M, Skotsimara G, Totlis T, Apostolidis S, Panagiotopoulos NA, Skandalakis P. The ossified pterygoalar ligament: An anatomical study with pathological and surgical implications. J Craniomaxillofac Surg 2014; 42:e266-270.

61. Namking M, Boonruangsri P, Woraputtaporn W, Guldner FH. Communication between the facial and auriculotemporal nerves. J Anat 1994; 185 ( Pt 2):421-426.

62. Kwak HH, Park HD, Youn KH, Hu KS, Koh KS, Han SH, Kim HJ. Branching patterns of the facial nerve and its communication with the auriculotemporal nerve. Surg Radiol Anat 2004; 26:494-500.

63. Diamond M, Wartmann CT, Tubbs RS, Shoja MM, Cohen-Gadol AA, Loukas M. Peripheral facial nerve communications and their clinical implications. Clin Anat 2011; 24:10-18.

64. Komarnitki I, Tomczyk J, Ciszek B, Zalewska M. Proposed classification of auriculotemporal nerve, based on the root system. PLoS One 2015; 10: e0123120.

65. Kim SY, Hu KS, Chung IH, Lee EW, Kim HJ. Topographic anatomy of the lingual nerve and variations in communication pattern of the mandibular nerve branches. Surg Radiol Anat 2004; 26:128-135.

66. Shimokawa T, Akita K, Sato T, Ru F, Yi SQ, Tanaka S. Penetration of muscles by branches of the mandibular nerve: $A$ possible cause of neuropathy. Clin Anat 2004; 17:2-5.

67. Soni S, Rath G, Suri R, Vollala VR. Un- 
usual organization of auriculotemporal nerve and its clinical implications. J Oral Maxillofac Surg 2009; 67:448-450.

68. Bergman RA, Afifi AK, Miyauchi R, D'Alessandro MP. Common variations in configuration, relationships, and formation of the auriculotemporal nerve; lateral view., Illustrated Encyclopedia of Human Anatomic Variation: Opus III: Nervous System, 2017. www.anatomyatlases. org/AnatomicVariants/NervousSystem/ Images/18.shtml

69. Isberg AM, Isacsson G, Williams WN, Loughner BA. Lingual numbness and speech articulation deviation associated with temporomandibular joint disk displacement. Oral Surg Oral Med Oral Pathol 1987; 64:9-14.

70. Ngeow WC, Chai WL. Numbness of the ear following inferior alveolar nerve block: The forgotten complication. $\mathrm{Br}$ Dent J 2009; 207:19-21.

71. Kim HJ, Kwak HH, Hu KS, Park HD, Kang HC, Jung HS, Koh KS. Topographic anatomy of the mandibular nerve branches distributed on the two heads of the lateral pterygoid. Int J Oral Maxillofac Surg 2003; 32:408-413.

72. Akita K, Shimokawa T, Sato T. Positional relationships between the masticatory muscles and their innervating nerves with special reference to the lateral pterygoid and the midmedial and discotemporal muscle bundles of temporalis. J Anat 2000; 197 ( Pt 2):291-302.

73. Schmalfuss IM, Tart RP, Mukherji S, Mancuso AA. Perineural tumor spread along the auriculotemporal nerve. AJNR Am J Neuroradiol 2002; 23:303-311.

74. Chan M, Dmytriw AA, Bartlett E, Yu E. Imaging of auriculotemporal nerve perineural spread. Ecancermedicalscience 2013; 7:374.

75. Upton AR, McComas AJ. The double crush in nerve entrapment syndromes. Lancet 1973; 2:359-362.

76. Costen JB. A syndrome of ear and sinus symptoms dependent upon disturbed function of the temporomandibular joint. Ann Otol Rhinol Laryngol 1934; 43:1-15.

77. Guyuron B, Riazi H, Long T, Wirtz E. Use of a doppler signal to confirm migraine headache trigger sites. Plast Reconstr Surg 2015; 135:1109-1112.

78. Damarjian E. Auriculo-temporal neuralgia--an original diagnostic and therapeutic approach. R I Med J 1970; 53:100-101.
79. Cartellieri M, Swoboda H. Neurofibroma of the auriculotemporal nerve. Eur Arch Otorhinolaryngol 2000; 257:396-398.

8o. Kragstrup TW, Christensen J, Fejerskov $\mathrm{K}$, Wenzel A. Frey syndrome-an underreported complication to closed treatment of mandibular condyle fracture? Case report and literature review. J Oral Maxillofac Surg 2011; 69:2211-2216.

81. Murayama RA, Stuginski-Barbosa J, Moraes NP, Speciali JG. Toothache referred from auriculotemporal neuralgia: Case report. Int Endod J 2009; 42:845-851.

82. Stuginski-Barbosa J, Murayama RA, Conti PC, Speciali JG. Refractory facial pain attributed to auriculotemporal neuralgia. J Headache Pain 2012; 13:415-417.

83. Ansari H, Robertson CE, Lane Jl, Viozzi CF, Garza I. Auriculotemporal neuralgia secondary to TMJ synovial cyst: A rare presentation of a rare entity. Headache 2013; 53:1662-1665.

84. Ruiz M, Porta-Etessam J, Garcia-Ptacek S, de la Cruz C, Cuadrado ML, Guerrero AL. Auriculotemporal neuralgia: Eight new cases report. Pain Med 2016; 17:1744-1748.

85. Frey L. Le syndrome du nerf auriculotemporal. Revue neurologique (Paris) 1923; 2:97-104.

86. Kryshtalskyj B, Weinberg S. An assessment for auriculotemporal syndrome following temporomandibular joint surgery through the preauricular approach. J Oral Maxillofac Surg 1989; 47:3-6.

87. De Benedittis G. Auriculotemporal syndrome (frey's syndrome) presenting as tic douloureux. Report of two cases. J Neurosurg 1990; 72:955-958.

88. Swanson KS, Laskin DM, Campbell RL. Auriculotemporal syndrome following the preauricular approach to temporomandibular joint surgery. J Oral Maxillofac Surg 1991; 49:680-682.

89. Beyers MR, Teich S. Mandibular joint neuralgia (costen's syndrome). AMA Arch Intern Med 1952; 90:389-391.

90. McGrath CJ, Egbert MA, Tong DC, Myall RW. Unusual presentations of injuries associated with the mandibular condyle in children. $\mathrm{Br}$ ] Oral Maxillofac Surg 1996; 34:311-314.

91. Rustemeyer J, Eufinger H, Bremerich A. The incidence of frey's syndrome. J Craniomaxillofac Surg 2008; 36:34-37.

92. Michael LA. A perspective jaws revisited: Costen's syndrome. Ann Otol Rhinol Lar- yngol 1997; 106:820-822.

93. Turp JC, Minagi S. Palpation of the lateral pterygoid region in tmd--where is the evidence? J Dent 2001; 29:475-483.

94. Fernandes G, Franco AL, Goncalves DA, Speciali JG, Bigal ME, Camparis CM. Temporomandibular disorders, sleep bruxism, and primary headaches are mutually associated. J Orofac Pain 2013; 27:14-20.

95. Trescot AM. Local anesthetic "resistance". Pain Physician 2003; 6:291-293.

96. Levin M. Nerve blocks and nerve stimulation in headache disorders. Techniques in Regional Anesthesia and Pain Management 2009; 13:42-49.

97. Donlon WC, Truta MP, Eversole LR. A modified auriculotemporal nerve block for regional anesthesia of the temporomandibular joint. J Oral Maxillofac Surg 1984; 42:544-545.

98. Kerr R, Pagliero D. in Warman P, Conn D, Nicholls B, Wilkinson D (eds). Regional anaesthesia, stimulation, and ultrasound techniques. Oxford University Press Oxford, UK, 2014.

99. Shankar H, Brethauer J. Ultrasound guided steroid injection for auriculotemporal neuralgia. Anesthesiology 2007; 107: A903.

100. Waldman S. Waldman's comprehensive atlas of diagnostic ultrasound of painful conditions. Wolters Kluwer, Philadelphia, PA, 2016.

101. Guyuron B, Tucker T, Davis J. Surgical treatment of migraine headaches. Plast Reconstr Surg 2002; 109:2183-2189.

102. Faber C, Garcia RM, Davis J, Guyuron B. A socioeconomic analysis of surgical treatment of migraine headaches. Plast Reconstr Surg 2012; 129:871-877.

103. Guyuron B, Harvey D, Reed D. A prospective randomized outcomes comparison of two temple migraine trigger site deactivation techniques. Plast Reconstr Surg 2015; 136:159-165.

104. McGeeney BE. Migraine trigger site surgery is all placebo. Headache 2015; 55:1461-1463.

105. McGeeney BE. Migraine trigger site surgery is all placebo: A response. Headache 2016; 56:779-781.

106. de Ru JA. Migraine trigger site surgery is all placebo. Headache 2016; 56:776-778.

107. Ramirez-Castaneda J, Jankovic J, Comella C, Dashtipour K, Fernandez HH, Mari Z. Diffusion, spread, and migration of botulinum toxin. Mov Disord 2013; 
28:1775-1783.

108. Hsu TS, Dover JS, Arndt KA. Effect of volume and concentration on the diffusion of botulinum exotoxin a. Arch Dermatol 2004; 140:1351-1354.

109. Guyuron B, Kriegler JS, Davis J, Amini SB. Comprehensive surgical treatment of migraine headaches. Plast Reconstr Surg 2005; 115:1-9.

110. Cantarella G, Berlusconi A, Mele V, Cogiamanian $\mathrm{F}$, Barbieri S. Treatment of frey's syndrome with botulinum toxin type b. Otolaryngol Head Neck Surg 2010; 143:214-218.

111. Simopoulos T, Bajwa Z, Lantz G, Lee S, Burstein R. Implanted auriculotemporal nerve stimulator for the treatment of refractory chronic migraine. Headache 2010; 50:1064-1069.

112. Deshpande KK, Wininger KL. Feasibility of combined epicranial temporal and occipital neurostimulation: Treatment of a challenging case of headache. Pain Physician 2011; 14:37-44.

113. Aksu F, Akyer SP, Kale A, Geylan S, Gayretli O. The localization and morphology of pterion in adult West Anatolian skulls. J Craniofac Surg 2014; 25:1488-1491.

114. Guyuron B, Nahabet E, Khansa I, Reed $D$, Janis JE. The current means for detection of migraine headache trigger sites. Plast Reconstr Surg 2015; 136:860-867.

115. Gee JR, Ishaq Y, Vijayan N. Postcraniotomy headache. Headache 2003; 43:276-278.

116. Fogaca WC, Fereirra MC, Dellon AL. Infraorbital nerve injury associated with zygoma fractures: Documentation with neurosensory testing. Plast Reconstr Surg 2004; 113:834-838.

117. Caulley L, Hong P. Pediatric auriculotemporal nerve (Frey) syndrome. CMA] 2013; 185:504.
118. Dizon MV, Fischer G, Jopp-McKay A Treadwell PW, Paller AS. Localized facial flushing in infancy. Auriculotemporal nerve (frey) syndrome. Arch Dermatol 1997; 133:1143-1145.

119. Ibrahim LF, Brenner C, McMenamin J, Webb D. Frey syndrome in neurofibromatosis 1. BM] Case Rep 2011; 2011EPub Mar 15, 2011..

120. Giamberardino MA, Tafuri E, Savini A, Fabrizio A, Affaitati G, Lerza R, Di lanni L, Lapenna D, Mezzetti A. Contribution of myofascial trigger points to migraine symptoms. J Pain 2007; 8:869-878.

121. Karahaliou M, Vaiopoulos G, Papaspyrou S, Kanakis MA, Revenas K, Sfikakis PP. Colour duplex sonography of temporal arteries before decision for biopsy: A prospective study in 55 patients with suspected giant cell arteritis. Arthritis Res Ther 2006; 8:R116. 